\title{
Numerical Study of Three-Dimensional Mixed Convection in an Eccentric Annulus
}

\author{
A. B. Rahimi* \\ Ferdowsi University of Mashhad, 91775 Mashhad, Iran \\ and \\ A. Abedinit \\ Islamic Azad University, Semnan, Iran

\section{DOI: $\underline{10.2514 / 1 . T 4155}$}

\begin{abstract}
Mixed convection of air with a Prandtl number of 0.7 in eccentric horizontal annuli is numerically investigated. The inner cylinder is at a higher temperature, while the inner and outer cylinders can be rotated either clockwise or counterclockwise with a constant angular velocity. The effects of various parameters, such as the eccentricity of the annulus and the Rayleigh number, are studied using a three-dimensional model. The Navier-Stokes equations, along with the energy equation, are solved in an orthogonal structured grid of a bipolar coordinate system employing a finite volume method based on the SIMPLE algorithm. Here, both steady and unsteady results are presented in two separate codes. Three-dimensional considerations lead to a complicated flow pattern, whereas Taylor vortices have a major role on heat and flow characteristics. It is shown that the axial component of velocity in some configurations has a considerable value, therefore, flow pattern and heat transfer characteristics change in comparison with a twodimensional approach. Eccentricity leads to a different flow pattern in the upper and lower parts of the annulus. Mean and local heat transfer results are obtained. The physics of the flow underlying the observed heat transfer behavior is revealed by the velocity vectors and the isotherm plots of the numerical solutions. Results show that flow and heat transfer are strongly influenced by the eccentricity of the inner cylinder and Raleigh number, and that threedimensionality consideration is inevitable.
\end{abstract}

\section{Nomenclature}

$a$

$E$

e

$g$

Gr

$H$

$h$

L

m

$N$

$n$

$N u_{i}, N u_{o}$

$\bar{N} u_{i}, \bar{N} u_{o}$

$P$

$p$

$\mathrm{Pr}$

$r_{i}, r_{o}$

$R a$

$R e_{i}, R e_{o}$

S

$T$
$=$ dimensionless eccentricity

$=$ eccentricity, $\mathrm{m}$

$=$ acceleration of gravity, $\mathrm{m} / \mathrm{s}^{2}$

$=$ Grashof number

$=$ dimensionless coordinate transformation factor, $h / L$

$=$ coordinate transformation scale factor, $\mathrm{m}$

$=r_{0}-r_{i}, \mathrm{~m}$

$=$ number of grids in $\xi$ direction

$=$ radius ratio, $r_{i} / r_{o}$

$=$ number of grids in $\eta$ direction

$=$ local Nusselt numbers at the inner and outer cylinders, respectively

$=$ mean Nusselt numbers at the inner and outer cylinders, respectively

$=$ dimensionless pressure

$=$ pressure, pa

$=$ Prandtl number

$=$ radius of the inner and outer cylinders, respectively

$=$ Rayleigh number based on the gap width

$=$ dimensionless velocity or Reynolds number at the inner and outer cylinders, respectively

$=$ source term in momentum equations

$=$ temperature, $\mathrm{k}$
Received 26 March 2013; revision received 12 July 2013; accepted for publication 13 July 2013; published online 5 September 2013. Copyright (C) 2013 by the American Institute of Aeronautics and Astronautics, Inc. All rights reserved. Copies of this paper may be made for personal or internal use, on condition that the copier pay the $\$ 10.00$ per-copy fee to the Copyright Clearance Center, Inc., 222 Rosewood Drive, Danvers, MA 01923; include the code 1533-6808/13 and $\$ 10.00$ in correspondence with the CCC.

*Faculty of Engineering, P.O. Box No. 91775-1111; rahimiab@um.ac.ir (Corresponding Author).

${ }^{\dagger}$ Assistant Professor, Mechanical Engineering Department, Semnan Branch, P.O. Box No.35131-37111; ahad_abedini@yahoo.com.

\begin{tabular}{|c|c|c|}
\hline & $=$ & $\mathrm{s}$ \\
\hline$T_{h}, T_{c}$ & $=$ & $\begin{array}{l}\text { temperatures at the inner and outer cylinders, } \\
\text { respectively }\end{array}$ \\
\hline & $=$ & mean temperature \\
\hline$U_{\zeta}, U_{\eta}, U_{Z}$ & $=$ & $\begin{array}{l}\text { dimensionless velocity in the } \zeta, \eta \text {, and } Z \\
\text { direction, respectively }\end{array}$ \\
\hline $\begin{array}{l}u_{\zeta}, u_{\eta} \\
u_{Z}(\mathrm{~m} / \mathrm{s})\end{array}$ & $=$ & velocity in the $\zeta, \eta$, and $Z$ direction, respectively \\
\hline$U, V, W$ & $=$ & velocity in the $x, y$, and $z$ direction respectively \\
\hline$x, y, z$ & $=$ & $\begin{array}{l}\text { coordinate variables in the Cartesian coordinate } \\
\text { system }\end{array}$ \\
\hline$Z$ & $=$ & nondimensional coordinate variable $z$ \\
\hline$Z_{1}$ & $=$ & annulus length \\
\hline$\alpha$ & $=$ & thermal diffusivity, $\mathrm{m}^{2} / \mathrm{s}$ \\
\hline$\beta$ & $=$ & coefficient of thermal expansion, $\mathrm{k}^{-1}$ \\
\hline$\eta_{i}, \eta_{o}$ & $=$ & $\begin{array}{l}\text { values of } \eta \text { on the inner and outer cylinders, } \\
\text { respectively }\end{array}$ \\
\hline$\theta$ & $=$ & dimensionless temperature \\
\hline$\xi, \eta$ & $=$ & $\begin{array}{l}\text { coordinate variables in the bipolar coordinate } \\
\text { system }\end{array}$ \\
\hline$\sigma$ & $=$ & $\begin{array}{l}\text { ratio of inner cylinder diameter to gap } \\
\text { width, } D_{i} / L\end{array}$ \\
\hline$\tau$ & $=$ & dimensionless time \\
\hline$v$ & $=$ & kinematic viscosity, $\mathrm{m}^{2} / \mathrm{s}$ \\
\hline
\end{tabular}

\section{Introduction}

$\mathbf{T}$ HE mixed convection problem in an annulus between cylinders has attracted special attention due to its wide range of engineering applications, such as mixtures, thermal energy storage systems, electrical components cooling, double pipe heat exchangers designed for chemical processes and food industries, and nuclear reactors. A good overview on concentric and eccentric annuli is carried out by Kuehn and Goldstein $[1,2]$. They measured the heat transfer coefficients in air and water in concentric and eccentric horizontal annuli. Their experimental data have commonly been used to validate most of the recent numerical studies. Later, Macleod and Bishop [3] performed several measurements of overall heat transfer rates and profiles of the time-averaged and fluctuations of the temperature field for fully turbulent natural convection. Shahraki [4] 
demonstrated the effect of temperature-dependent properties on the streamlines and temperature distributions in a concentric annulus. The varying viscosity had the strongest effect on the flowfield, whereas the thermal conductivity had the strongest effect on temperature profiles. Natural convection of a micropolar fluid in an eccentric annulus enclosure was studied by Char and Lee [5]. An unsteady natural convection in a horizontal annulus was investigated by Mizushima et al. [6]. Instability analyses for natural convection in horizontal annuli have been extensively addressed in the literature. Petrone et al. [7] numerically studied the linear instability of twodimensional (2-D) natural convection in air-filled horizontal annuli and a map of possible flow patterns was established. Numerical results of the turbulent flow in a 2-D domain were presented by Farouk and Guceri [8]. In their studies, the natural convection was considered in the annulus between two horizontal concentric cylinders. The stream-vorticity equation was discretized employing finite difference techniques and turbulence was modeled using the $\kappa-\varepsilon$ approach for Rayleigh numbers above 105. The work by Char and Hsu [9] on turbulence modeling of natural convection in cylindrical horizontal annuli proposed a comparison of the different turbulence models with the suggestion of a better modeling practice. According to this paper, the nonlinear mode produces better results, especially at higher Rayleigh numbers. Padilla et al. [10] investigated laminar and unsteady natural convection at low Rayleigh numbers in a concentric annulus. In some applications, fin is used to increase the heat transfer rate in the axial direction. Chai and Patankar [11], Desrayaud et al. [12], Patankar et al. [13], and Rustum and Soliman [14] investigated the effect of fins attached on the inner and outer cylinders on the fluid flow and heat transfer in annuli by analyzing the result obtained from the numerical solution of 2-D and steady-state governing equations. Dyko et al. [15] presented the numerical and experimental buoyancy driven flow in an annulus between two horizontal coaxial cylinders at Rayleigh numbers exceeding the critical value. Mixed convection of air between two horizontal concentric cylinders with a cooled rotating outer cylinder has been investigated by Yoo [16]. He found three flow regimes in an annulus: two, one, and no eddy configurations. Habib and Negm [17] numerically investigated the fully developed laminar mixed convection in horizontal concentric annuli for the case of nonuniform circumferential heating. Two heating conditions were explored, one in which the top half of the inner surface of the inner cylinder is uniformly heated whereas the bottom half is kept insulated, and the other in which the heated and the insulated surfaces were reversed. It was found that the bottom heating arrangement gives rise to a vigorous secondary flow, resulting in much higher average Nusselt numbers than those of pure forced convection. Other authors (such as Glakpe et al. [18], Glakpe and Watkins [19], Hessami et al. [20], Kumar [21], Soliman and Mirza [22], Tsui and Tremblay [23], Yang et al. [24], Van de Sande and Hamer [25], Pepper and Kooper [26], Teertstra et al. [27], and Khan et al. [28,29]) did experimental and numerical studies to investigate geometry, boundary condition, fluid properties, steady, and unsteady effects in a 2-D concentric and eccentric annulus.

As mentioned previously, many numerical and experimental studies have been done in a horizontal annulus. In most of these studies, a 2-D model was used, in which the annuli are assumed to be infinitely long. However, in practical applications, the viscous shearing effects at the end walls could lead to erroneous results. There are limited investigations considering a three-dimensional (3-D) annulus. Vafai and Ettefagh [30] performed a 3-D natural convection simulation in a closed horizontal annulus. They carried out a detailed analysis of the 3-D flow and temperature field. Using the finite element method, Vafai and Desai [31] simulated buoyancy induced flow and heat transfer in closed and open-ended annular cavities. Numerical investigations of 3-D natural convection flow were accomplished by Yeh [32]. He examined different kinds of boundary conditions for natural convection problems. Lee [33] treated this problem over a good range of Rayleigh numbers, allowing for both horizontal and vertical eccentricities of the inner cylinder. It was concluded that the mean Nusselt number increased with the increasing of Rayleigh number at a given angular velocity and decreased with the increasing of rotation speed, while all other parameters were kept constant. Yang and Farouk [34] studied the mixed convection problem in a 3-D concentric annulus. Their simulation covers a wide range of Reynolds and Grashof numbers.

To the best of our knowledge, there is no existing investigation about a mixed convection problem in an eccentric 3-D annulus. The present work deals with the flow and mixed convection in a horizontal eccentric annulus where its inner and outer walls are kept at hot and cold temperatures $\left(T_{h}, T_{c}\right)$, respectively. Here, the 3-D full NavierStokes equations, along with the energy equation, are solved in an orthogonal structured grid of a bipolar coordinate system employing a finite volume method based on the SIMPLE algorithm. The eccentric problem can be modeled by both general and bipolar coordinate systems. The bipolar coordinate system not only produces the orthogonal grid system, but can also serve many purposes in the study of eccentric mixed convection annuli. In this coordinate system, there is no need to have two computational and physical domains compared to the general coordinate system. In addition, enforcing boundary conditions with the applications of rotating cylinders are simply implemented.

\section{Mathematical Modeling}

The geometry of the annulus is illustrated in Fig. 1. The inner and outer cylinders are kept at hot and cold temperatures $\left(T_{h}, T_{c}\right)$, respectively. Both of the cylinders can rotate alone or simultaneously with a constant angular velocity in either direction. Governing equations including continuity, momentum, and energy equations are written in the bipolar coordinate system for convenience. The two directions involving $(\xi, \eta)$ are shown in Fig. 2. The key feature of this coordinate system is the orthogonality of the generated grid and its fitness to the physical domain, which reduces the numerical errors caused by flux computation, see [35].

The transformation relations between bipolar and Cartesian coordinate systems are as follows [34]

$$
E=\frac{e}{r_{o}-r_{i}}, \quad N=\frac{r_{i}}{r_{o}}
$$

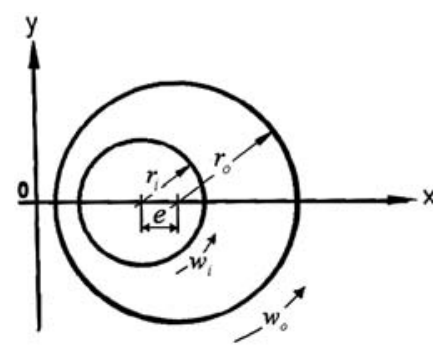

Fig. 1 Geometry of the annulus.

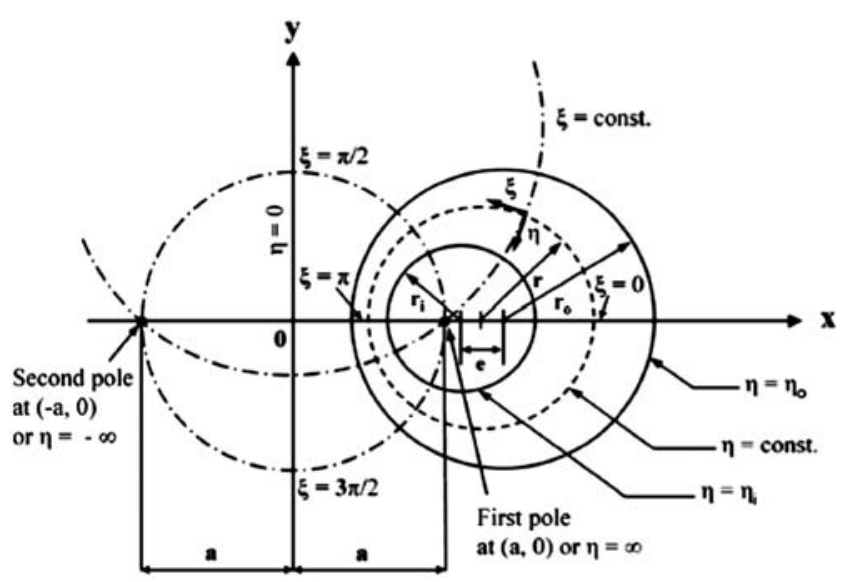

Fig. 2 Bipolar coordinate system. 


$$
\begin{gathered}
\eta_{i}=\cosh ^{-1}\left(\left(N\left(1+E^{2}\right)+\left(1-E^{2}\right)\right) /(2 N E)\right) \\
\eta_{o}=\cosh ^{-1}\left(\left(N\left(1-E^{2}\right)+\left(1+E^{2}\right)\right) /(2 E)\right) \\
a=r_{i} \sinh \left(\eta_{i}\right)
\end{gathered}
$$$$
x=\frac{a \sinh \eta}{\cosh \eta-\cos \xi}, \quad y=\frac{a \sin \xi}{\cosh \eta-\cos \xi}
$$

where $\xi$ varies from 0 to $2 \pi$ and $\eta$ varies over the range of $-\infty$ to $\infty$. As illustrated in Fig. 2, the locus of the constant $-\eta$ lines is a set of circles whose centers are located on the $x$ axis at the points $[a \cot (\eta), 0]$ and the locus of the constant $-\xi$ lines are circles whose radii are $a / \sin (\xi)$ with centers at the point $[0, \cot (\xi)]$ on the $y$-axis. Constant $-\eta$ circles are used to generate eccentric cylinders and the values of $\eta=\eta_{i}$ and $\eta=\eta_{o}$ represent the inner and outer cylinders, respectively.

Assuming Newtonian incompressible fluid in the presence of gravity, neglecting the radiation and viscous dissipation, and using the Boussinesqu approximation (considering constant properties except density in the buoyancy term), the governing equations in the bipolar coordinate system can be written as

$$
\begin{aligned}
& L=r_{o}-r_{i} \quad H=\frac{h}{L} \quad Z=\frac{z}{L} \quad U_{\zeta}=\frac{u_{\xi} L}{v} \\
& U_{\eta}=\frac{u_{\eta} L}{v} \quad U_{z}=\frac{u_{z} L}{v} \quad P=\frac{p L^{2}}{\rho v^{2}} \quad \theta=\frac{T-T_{c}}{T_{h}-T_{c}} \\
& \operatorname{Pr}=\frac{v}{\alpha} \quad G r=\frac{\beta g\left(T_{h}-T_{c}\right) L^{3}}{v^{2}} \quad \tau=\frac{t v}{L^{2}}
\end{aligned}
$$

Continuity

$$
\frac{1}{H^{2}}\left[\frac{\partial}{\partial \xi}\left(H U_{\xi}\right)+\frac{\partial}{\partial \eta}\left(H U_{\eta}\right)+H^{2} \frac{\partial U_{z}}{\partial Z}\right]=0
$$

$\xi$-momentum equation

$$
\begin{aligned}
\frac{\partial U_{\xi}}{\partial \tau}+ & \frac{1}{H^{2}}\left[\frac{\partial}{\partial \xi}\left(H U_{\xi}^{2}\right)+\frac{\partial}{\partial \eta}\left(H U_{\xi} U_{\eta}\right)+H^{2} \frac{\partial}{\partial Z}\left(U_{\xi} U_{Z}\right)\right] \\
= & -\frac{1}{H} \frac{\partial P}{\partial \xi}+\frac{1}{H^{2}}\left[\frac{\partial^{2} U_{\xi}}{\partial \xi^{2}}+\frac{\partial^{2} U_{\xi}}{\partial \eta^{2}}+H^{2} \frac{\partial^{2} U_{\xi}}{\partial Z^{2}}\right]+S_{\xi} \\
S_{\zeta} & =\frac{1}{H^{2}} \frac{\partial H}{\partial \xi} U_{\eta}^{2}-\frac{1}{H^{2}} \frac{\partial H}{\partial \eta} U_{\zeta} U_{\eta}+\frac{2}{H^{4}} \frac{\partial H}{\partial \xi} \frac{\partial H}{\partial \eta} U_{\eta}+\frac{2}{H^{3}} \frac{\partial H}{\partial \eta} \frac{\partial U_{\eta}}{\partial \xi} \\
& -\frac{2}{H^{4}}\left(\frac{\partial H}{\partial \eta}\right)^{2} U_{\xi}+\frac{1}{H^{3}} \frac{\partial^{2} H}{\partial \eta^{2}} U_{\xi}+\frac{1}{H^{3}} \frac{\partial^{2} H}{\partial \xi^{2}} U_{\xi}-\frac{2}{H^{3}} \frac{\partial H}{\partial \eta} \frac{\partial U_{\xi}}{\partial \eta} \\
& -\left(\frac{1-\cosh \eta \cos \xi}{\cosh \eta-\cos \xi}\right) G r \cdot \theta
\end{aligned}
$$

$\eta$-momentum equation

$$
\begin{aligned}
\frac{\partial U_{\eta}}{\partial \tau}+\frac{1}{H^{2}}\left[\frac{\partial}{\partial \xi}\left(H U_{\xi} U_{\eta}\right)+\frac{\partial}{\partial \eta}\left(H U_{\eta}^{2}\right)+H^{2} \frac{\partial}{\partial Z}\left(U_{\eta} U_{Z}\right)\right] \\
=-\frac{1}{H} \frac{\partial P}{\partial \eta}+\frac{1}{H^{2}}\left[\frac{\partial^{2} U_{\eta}}{\partial \xi^{2}}+\frac{\partial^{2} U_{\eta}}{\partial \eta^{2}}+H^{2} \frac{\partial^{2} U_{\eta}}{\partial Z^{2}}\right]+S_{\eta} \\
S_{\eta}=\frac{1}{H^{2}} \frac{\partial H}{\partial \eta} U_{\xi}^{2}-\frac{1}{H^{2}} \frac{\partial H}{\partial \xi} U_{\xi} U_{\eta}+\frac{2}{H^{4}} \frac{\partial H}{\partial \xi} \frac{\partial H}{\partial \eta} U_{\xi}+\frac{2}{H^{3}} \frac{\partial H}{\partial \xi} \frac{\partial U_{\xi}}{\partial \eta} \\
-\frac{2}{H^{4}}\left(\frac{\partial H}{\partial \xi}\right)^{2} U_{\eta}+\frac{1}{H^{3}} \frac{\partial^{2} H}{\partial \xi^{2}} U_{\eta}+\frac{1}{H^{3}} \frac{\partial^{2} H}{\partial \eta^{2}} U_{\eta}-\frac{2}{H^{3}} \frac{\partial H}{\partial \xi} \frac{\partial U_{\eta}}{\partial \xi} \\
-\left(\frac{\sinh \eta \sin \xi}{\cosh \eta-\cos \xi}\right) G r \cdot \theta
\end{aligned}
$$

Note that the last terms in $S_{\xi}$ and $S_{\eta}$ are obtained by decomposing buoyancy force in $\xi$ and $\eta$ directions, respectively.

$Z$-momentum equation

$$
\begin{gathered}
\frac{\partial U_{z}}{\partial \tau}+\frac{1}{H^{2}}\left[\frac{\partial}{\partial \xi}\left(H U_{\zeta} U_{z}\right)+\frac{\partial}{\partial \eta}\left(H U_{\eta} U_{z}\right)+H^{2} \frac{\partial}{\partial Z}\left(U_{z}^{2}\right)\right] \\
=-\frac{\partial P}{\partial Z}+\frac{1}{H^{2}}\left[\frac{\partial^{2} U_{z}}{\partial \xi^{2}}+\frac{\partial^{2} U_{z}}{\partial \eta^{2}}+\frac{\partial^{2} U_{z}}{\partial Z^{2}}\right]
\end{gathered}
$$

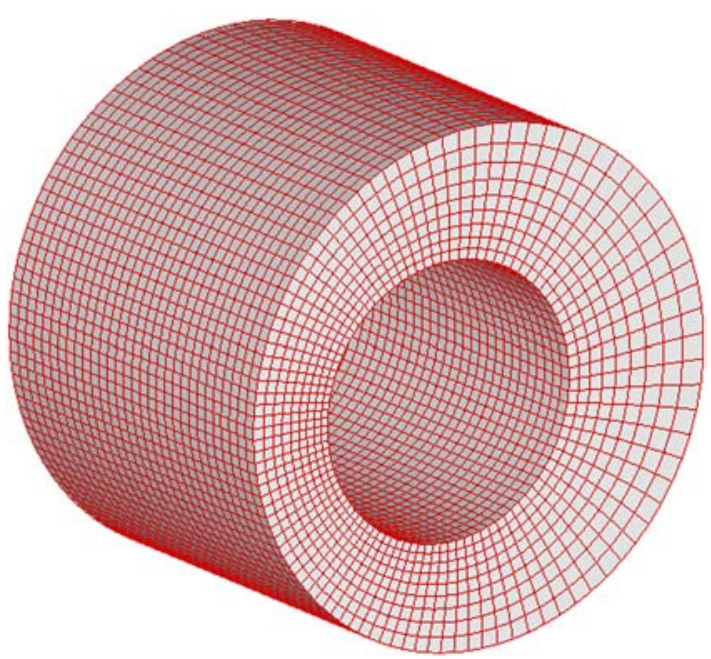

Fig. 3 Physical grid.

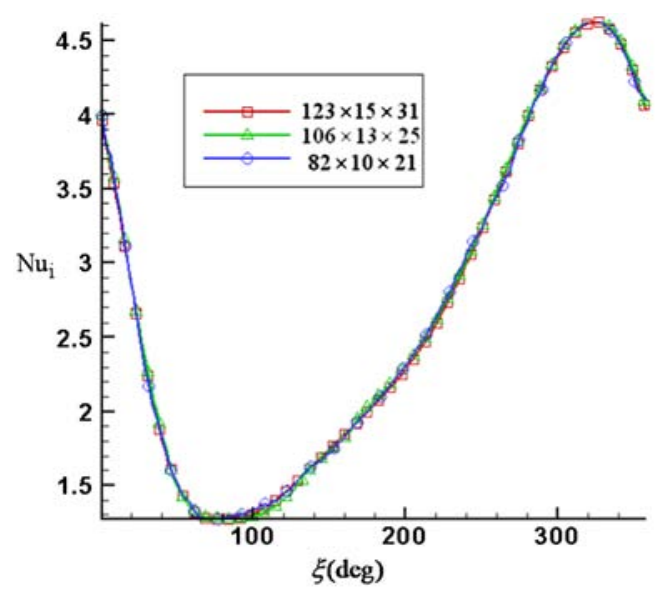

Fig. 4 Grid independency $(R a=5000, E=0.3, Z=1.5)$.

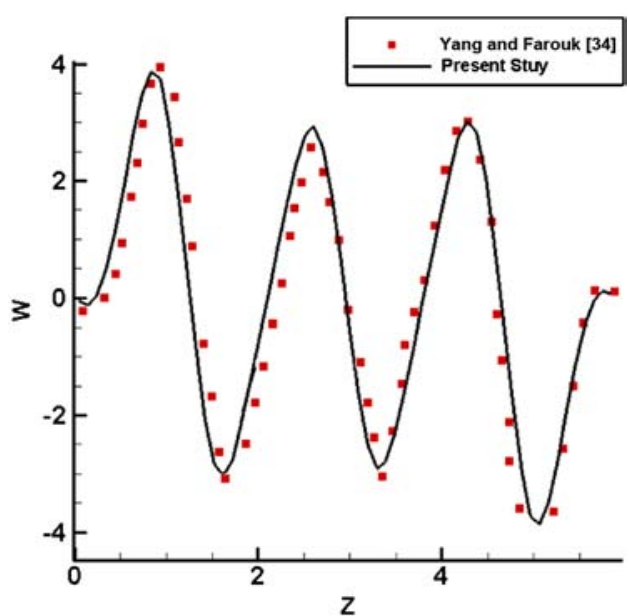

Fig. 5 Axial velocity comparison $\left(P r=0.72, R e_{i}=100, R a=0\right.$, $\left.Z_{1}=6, r=\left(r_{i}+r_{o}\right) / 2\right)$. 


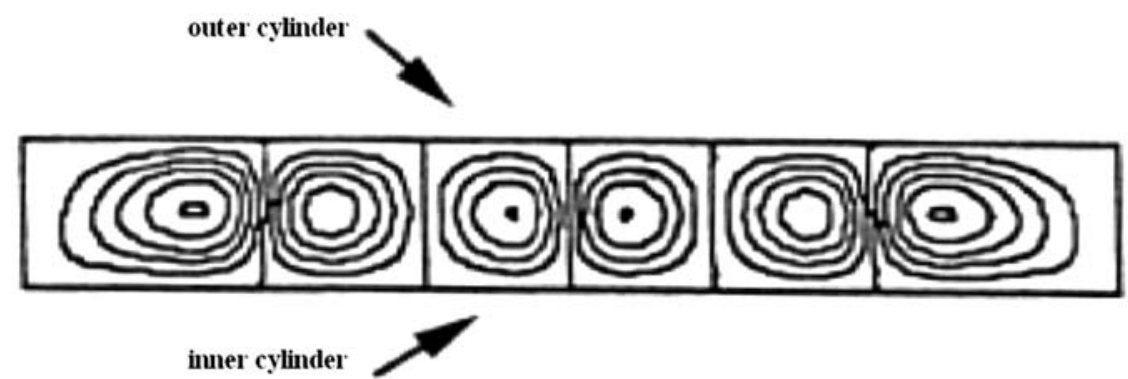

Yang and Farouk [34]

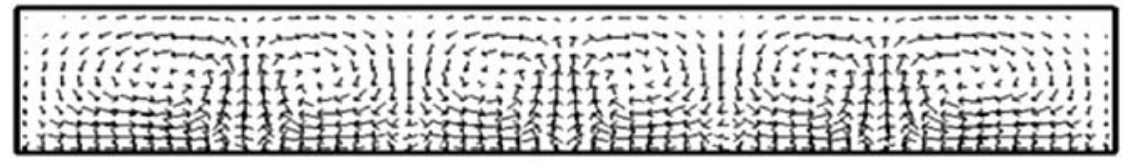

Present

Fig. 6 Streamline and velocity vector comparison $\left(\mathrm{Pr}=0.72, \boldsymbol{R e}_{i}=100, \mathrm{Ra}=\mathbf{0}, \mathrm{XZ}\right.$ plane $)$.

Energy equation

$$
\begin{aligned}
\frac{\partial \theta}{\partial \tau} & +\frac{1}{H^{2}}\left[\frac{\partial}{\partial \xi}\left(H U_{\xi} \theta\right)+\frac{\partial}{\partial \eta}\left(H U_{\eta} \theta\right)+H^{2} \frac{\partial}{\partial Z}\left(U_{z} \theta\right)\right] \\
& =\frac{1}{P r H^{2}}\left[\frac{\partial^{2} \theta}{\partial \xi^{2}}+\frac{\partial^{2} \theta}{\partial \eta^{2}}+\frac{\partial^{2} \theta}{\partial Z^{2}}\right]
\end{aligned}
$$

The dimensionless boundary conditions are

$$
\begin{aligned}
& \eta=\eta_{i} \rightarrow \quad \theta=1 \quad U_{\eta}=0 \quad U_{\xi}=R e_{i} \quad U_{z}=0 \\
& \eta=\eta_{o} \rightarrow \quad \theta=0 \quad U_{\eta}=0 \quad U_{\xi}=R e_{o} \quad U_{z}=0 \\
& Z=0 \rightarrow \quad \theta=0 \quad U_{\eta}=0 \quad U_{\xi}=0 \quad U_{z}=0 \\
& Z=Z_{1} \rightarrow \quad \theta=0 \quad U_{\eta}=0 \quad U_{\xi}=0 \quad U_{z}=0
\end{aligned}
$$
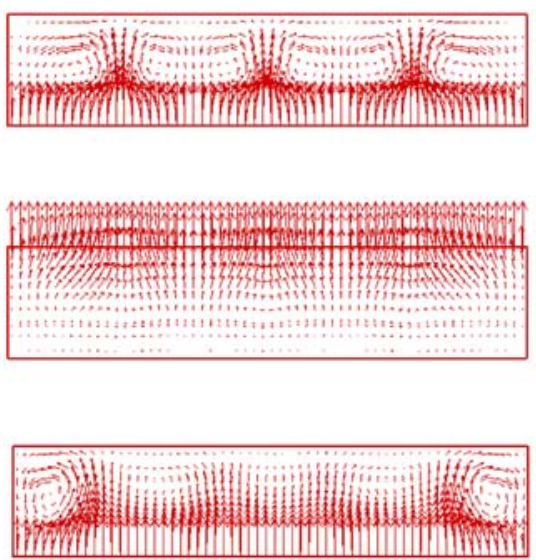

$R a=0$
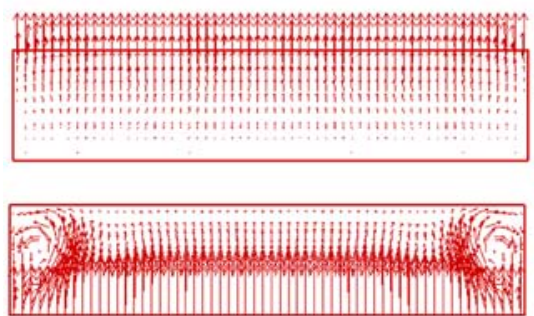

$R a=2000$

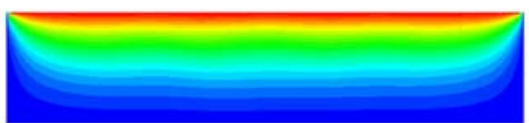

Note that the kinematic viscosity has been used here to nondimensionalize the velocity components. In this way, dimensionless velocity is changed to Reynolds number, which can be used for better interpretation of the results.

The distribution of the heat flux along the solid walls is examined through computing the local Nusselt number along the inner and outer cylinders
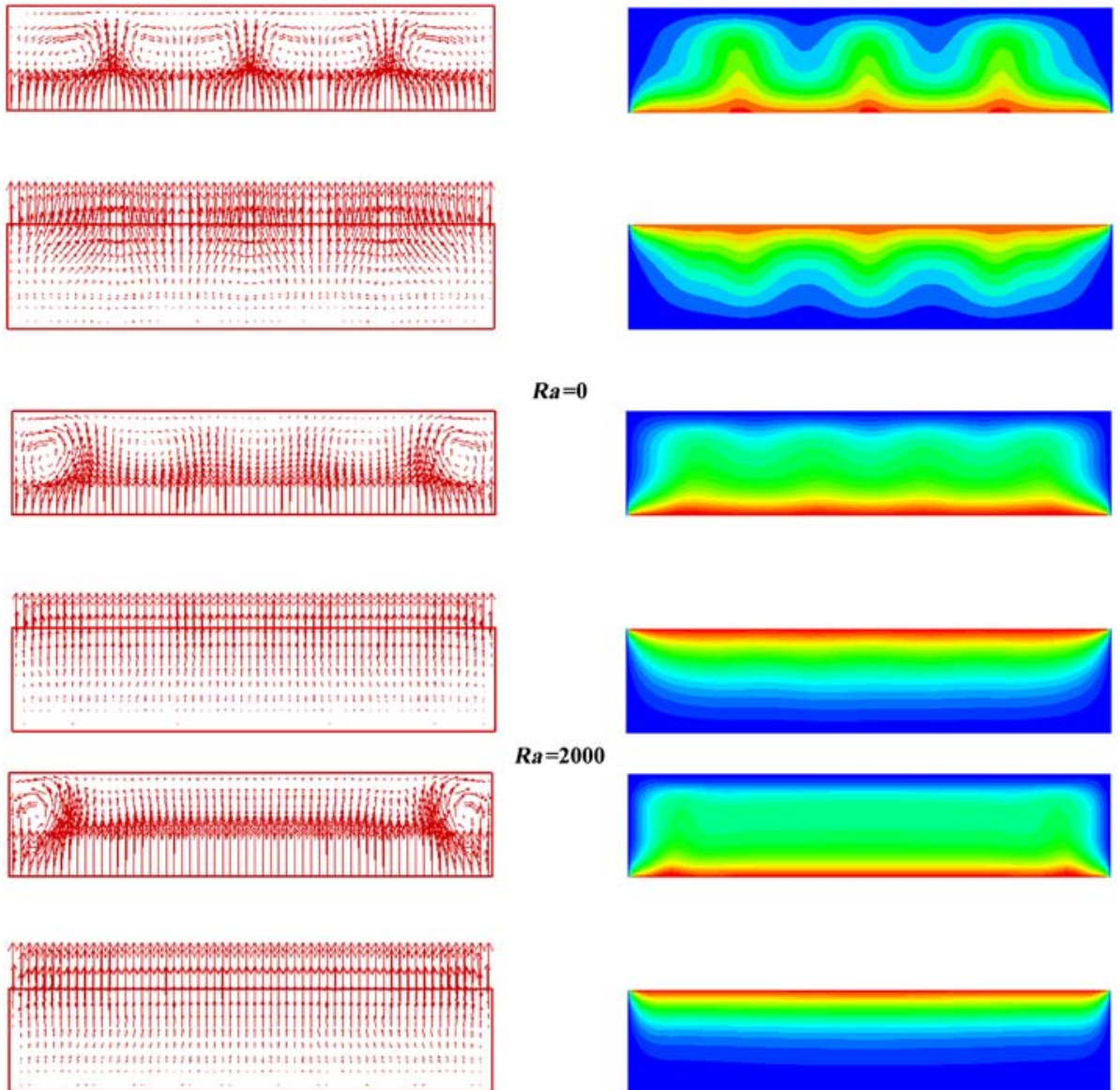

Fig. 7 Velocity vector and isotherms $\left(\operatorname{Re}_{i}=+100, E=0.1\right)$ 

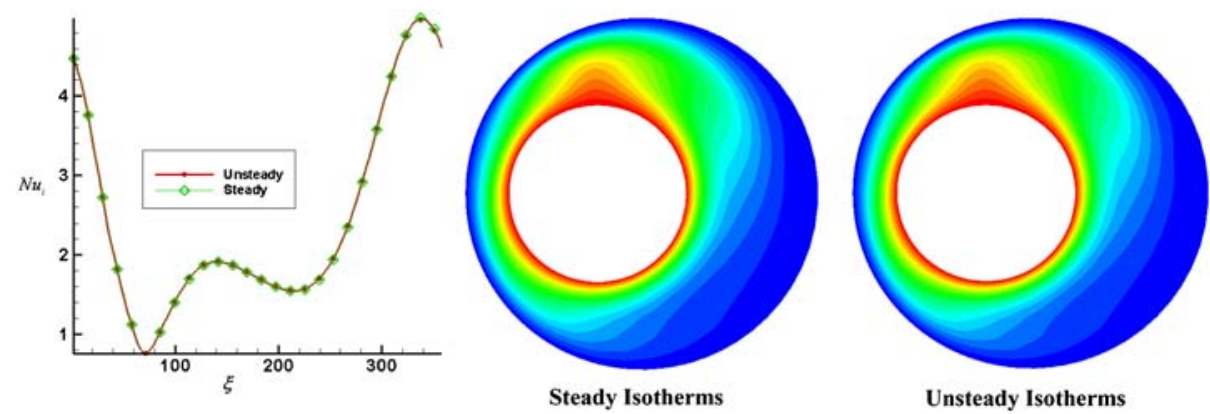

Fig. 8 Steady and unsteady comparison $\left(R a=5000, R e_{o}=+100, Z=1.5\right)$.

$N u_{i}(\xi)=\left.\frac{h_{\xi} L}{k}\right|_{\eta=\eta_{i}}=\left.\frac{\partial \theta}{\partial \eta}\right|_{\eta=\eta_{i}} \quad N u_{o}(\xi)=\left.\frac{h_{\xi} L}{k}\right|_{\eta=\eta_{o}}=\left.\frac{\partial \theta}{\partial \eta}\right|_{\eta=\eta_{o}}$

(15)

$$
\begin{aligned}
& \overline{N u_{i}}=\frac{1}{2 \pi Z_{1}} \int_{0}^{Z_{1}} \int_{0}^{2 \pi} N u_{i}(\xi) \mathrm{d} \xi \mathrm{d} Z \\
& \bar{N} u_{o}=\frac{1}{2 \pi Z_{1}} \int_{0}^{Z_{1}} \int_{0}^{2 \pi} N u_{\mathrm{o}}(\xi) \mathrm{d} \xi \mathrm{d} Z
\end{aligned}
$$

The average inner and outer Nusselt numbers are given by
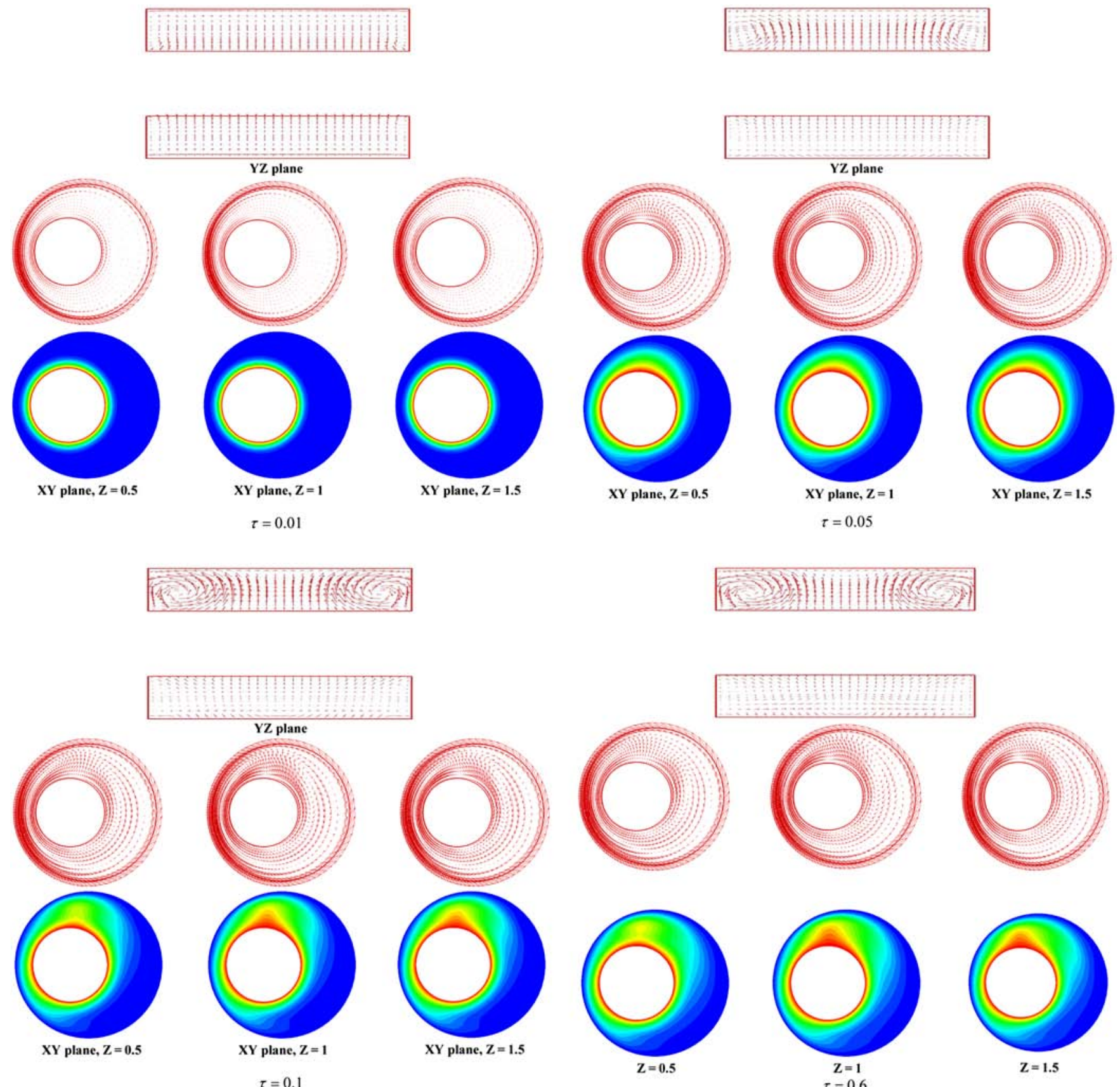

Fig. 9 Unsteady results $\left(R a=5000, R e_{o}=+100, E=0.5\right)$. 


\section{Numerical Procedure}

The finite volume method based on the SIMPLE algorithm, developed by Patankar [35], is used to solve the governing equations in the cylindrical bipolar coordinate system. Using this coordinate system has the privileges of orthogonality and simplicity of computing different fluxes involved. To the best of our knowledge, this procedure in the present geometry is carried out for the first time in this study. An easy method to generate the grid is to divide all the intervals into equal segments. If $m, n$, and $q$ represent the number of segments in $\xi, \eta$, and $Z$ directions, respectively, then

$$
H \Delta \xi=H \Delta \eta=\frac{2 \pi}{m}=\frac{\eta_{i}-\eta_{o}}{n}=\frac{Z_{1}}{q}
$$
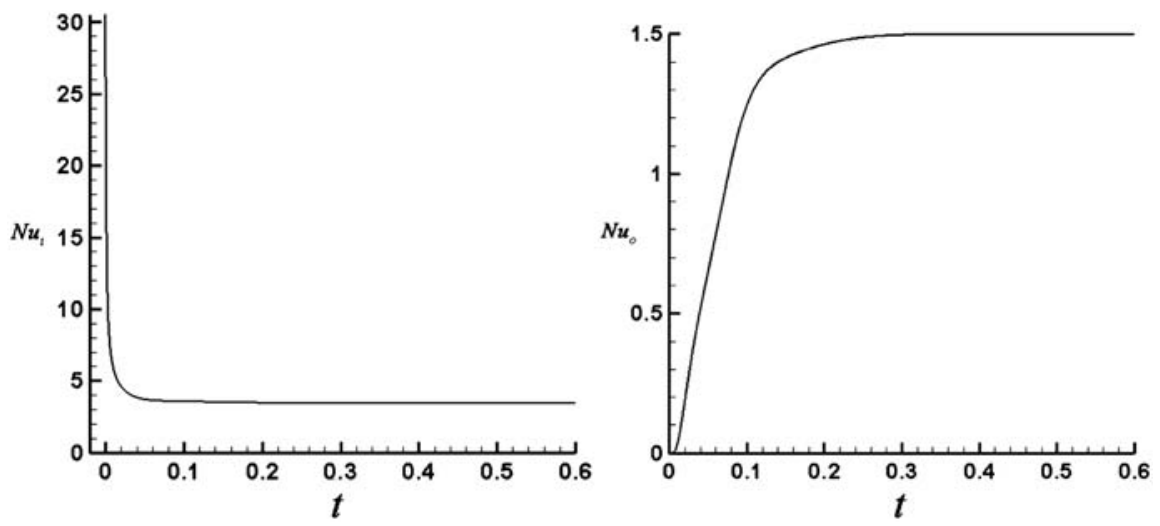

Fig. 10 Unsteady Nusselt number.
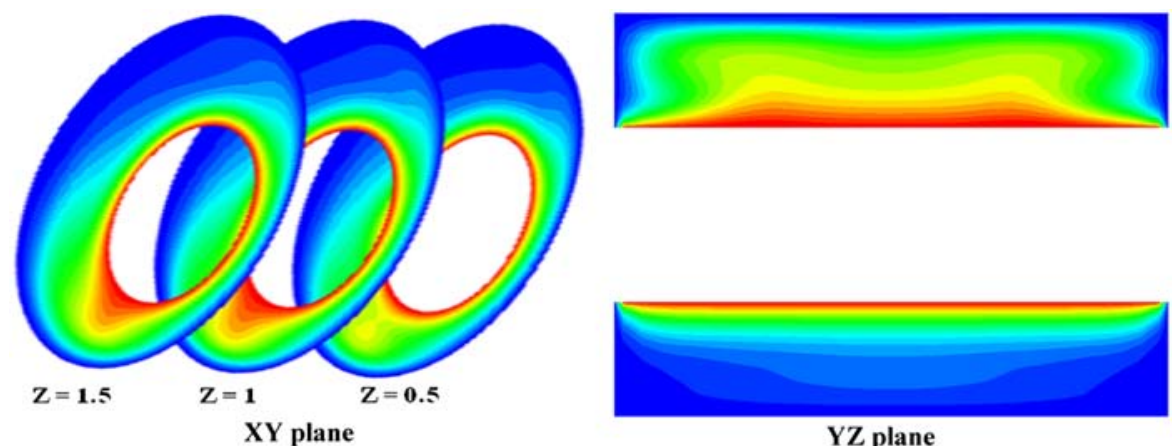

YZ plane

Fig. 11 Isotherms.
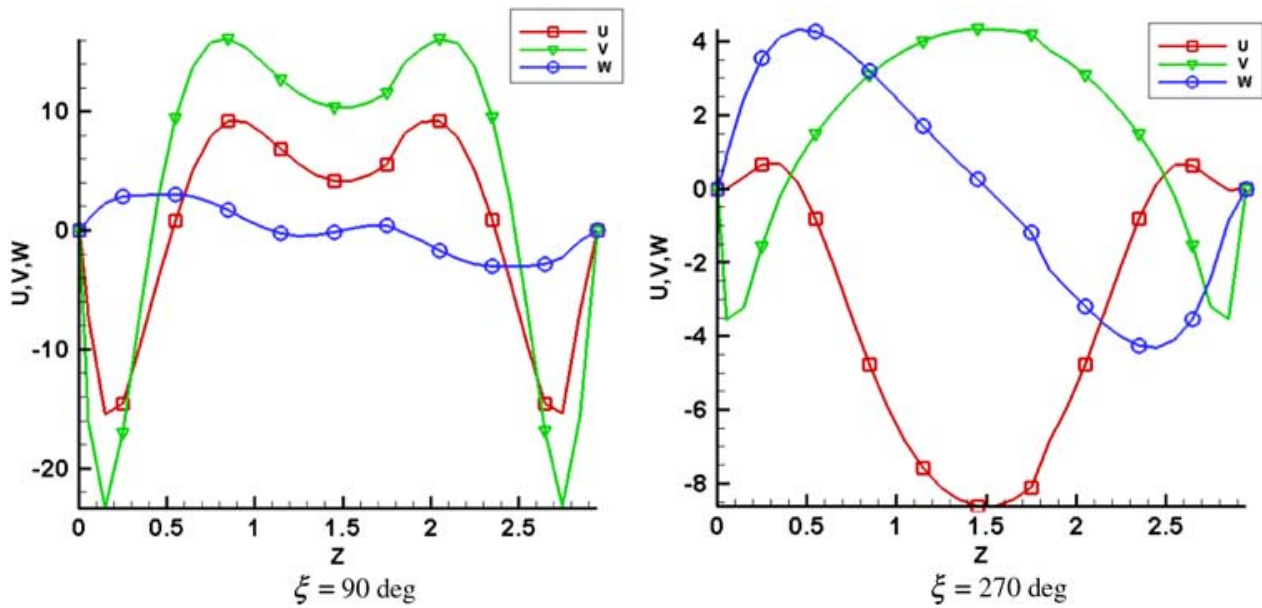

Fig. 12 Velocity magnitude $(R=3 / 2)$. 
generating a system of algebraic equations and the resulting tridiagonal matrix is solved by Tri-diagonal method algorithm solver. Here, the maximum error for the residuals for momentum and continuity equations is set to be of order of $O\left(10^{-5}\right)$. This value for energy equation is of $O\left(10^{-8}\right)$ [35]. It was shown that 6000 iterations were enough for all investigated values.

Results obtained here are validated by a simple case, which was previously completed. Axial velocity component $(W)$ for the case of pure forced convection is shown in Fig. $\underline{5}$. Forced convection is applied by rotating the inner cylinder at $R e_{i}=100$. Results presented by Yang and Farouk [34] have been reported for concentric annulus, but our simulation is performed for the eccentric one. By neglecting eccentricity $(E=0)$, our geometry is changed to concentric but noting the transformation relation between bipolar and Cartesian coordinate system, $E=0$ produces undefined values. To avoid this, we take $E=0.001$ as the concentric case. The slight difference between results by Yang and Farouk [34] can be due to this assumption. Streamlines and velocity vectors in Fig. 6 indicate good agreements.

\section{Results And Discussions}

The overall objective of the current investigation is to explore the characteristics of the laminar mixed convection heat transfer in a 3-D eccentric annulus. Results are generally in the form of velocity vectors, isotherms, Nusselt number, and velocity components. The Prandtl number is a constant throughout the paper and equals 0.7, while the Rayleigh number varies from $10^{3}$ to $2 \times 10^{4}$. Eccentricity $(E)$, which has a considerable effect on flow and heat transfer characteristics, varies from 0.1 to 0.5 . Both of the cylinders can rotate alone or simultaneously with a specific velocity to reach mixed convection situation. Note that the counterclockwise rotation is assumed to be positive, thus clockwise rotation is assumed to be negative. The results presented here are related to eccentric annulus with inner and outer dimensionless radius of one and two, respectively. Large values of annulus length cause the run time to increase. In addition, immoderate increasing of length does not show much difference in results but leading to the 2-D problem, which has already been investigated. To show the analysis leading to the 2-D problem for large $Z_{1}$, we take $Z_{1}=6$ and $R e_{i}=+100$ and Rayleigh number varies from 0 to 4000 . $R a=0$ means pure forced convection and increasing its value leads to the mixed convection phenomenon. As shown in Fig. 7, for $R a=0$, Taylor vortices are obviously formed, which create large gradients in temperature distribution and velocity vectors so we cannot use the 2-D simulation for pure forced convection. However, having large values of cylinder length and as $R a$ increases (mixed convection appears), Taylor vortices are omitted except at the two ends. Therefore, it can be shown that there is no need for a 3-D simulation at the middle of the annulus length for larger values of $Z_{1}=3.0$ in the mixed convection problem.
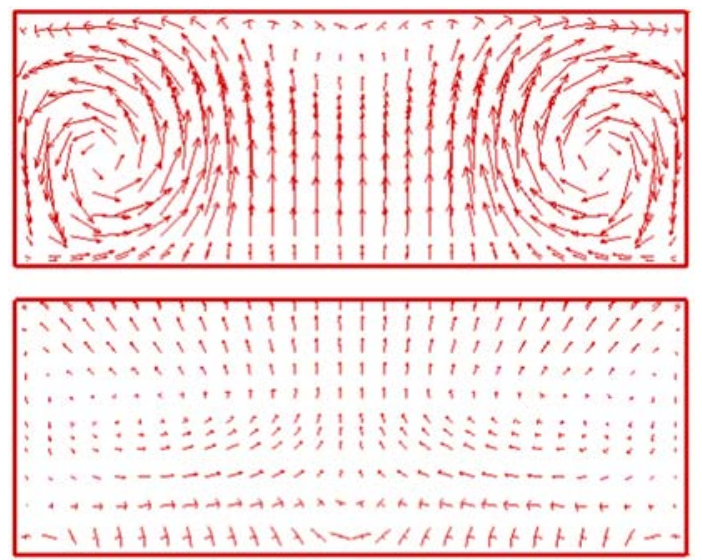

Fig. 13 Velocity vectors (YZ plane).
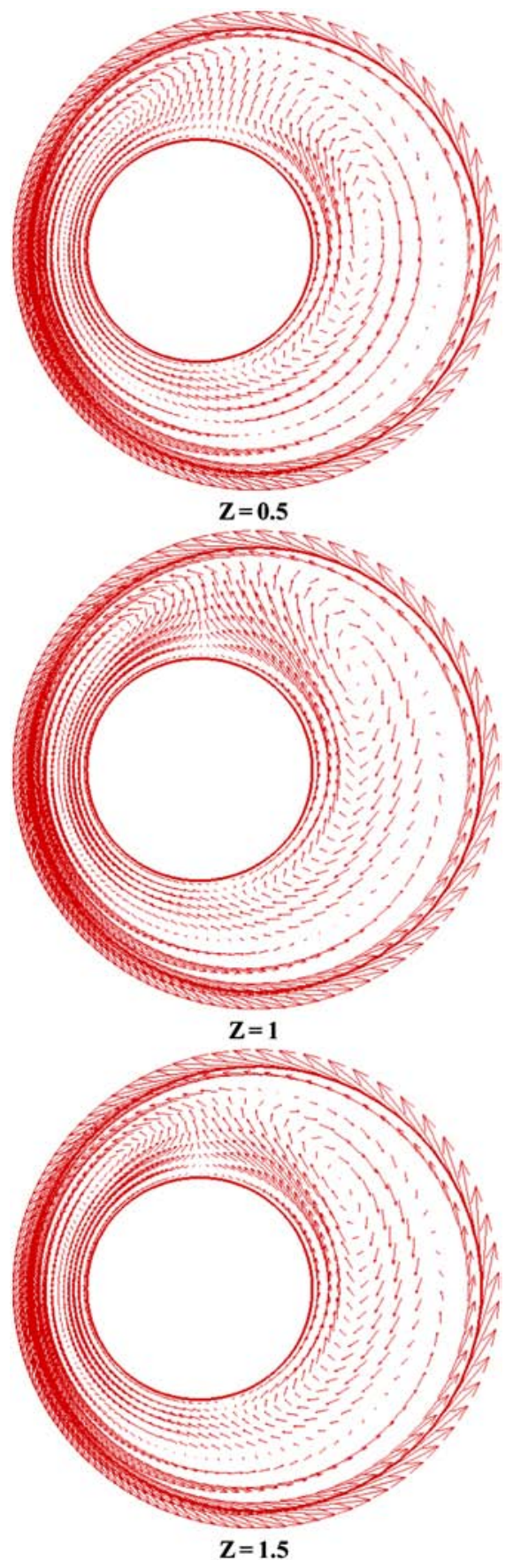

Fig. 14 Velocity vectors.

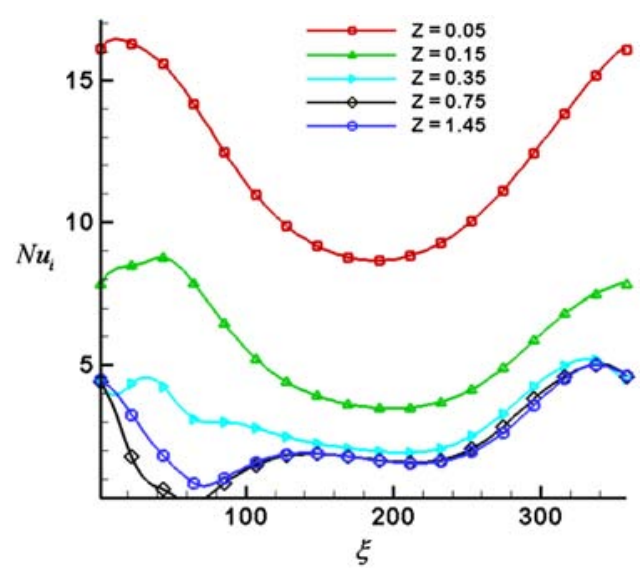

Fig. 15 Local Nusselt number (inner cylinder). 


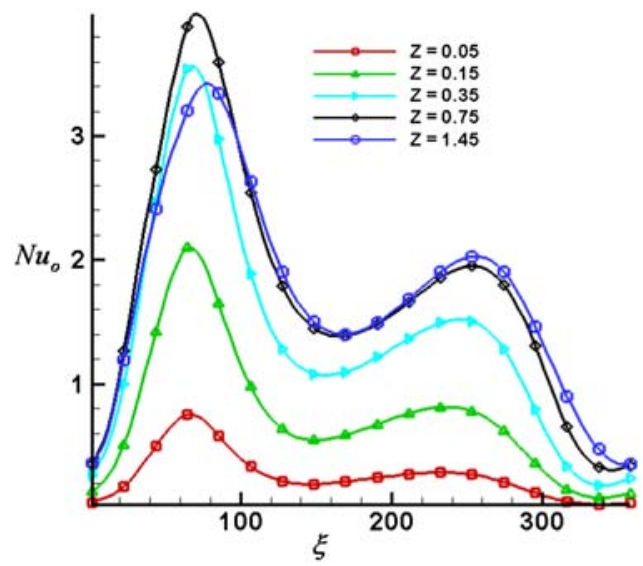

Fig. 16 Local Nusselt number (outer cylinder).

Flow in the annulus can be considered in the steady and unsteady form depending on particular applications. Here, both steady and unsteady results are presented and two separate codes are developed. Because no published results in the study of unsteady 3-D eccentric annulus exist, it is necessary to use steady results to validate the results. To achieve this purpose, the unsteady code is let to run until the results are invariant, which is known to be steady results, so we can compare these results with steady results extracted from the steady code. This comparison is presented in Fig. $\underline{8}$. As it can be seen, steady and unsteady results for Nusselt number and isotherms in the middle of the annulus length have excellent agreements.

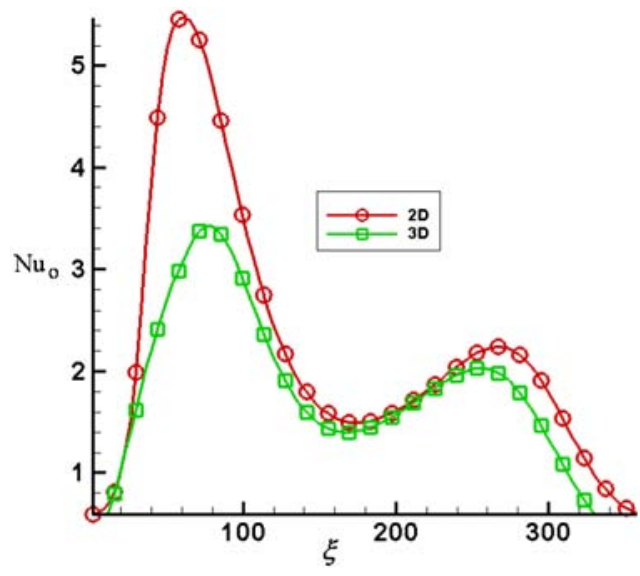

Fig. 17 2-D and 3-D Nusselt comparison.

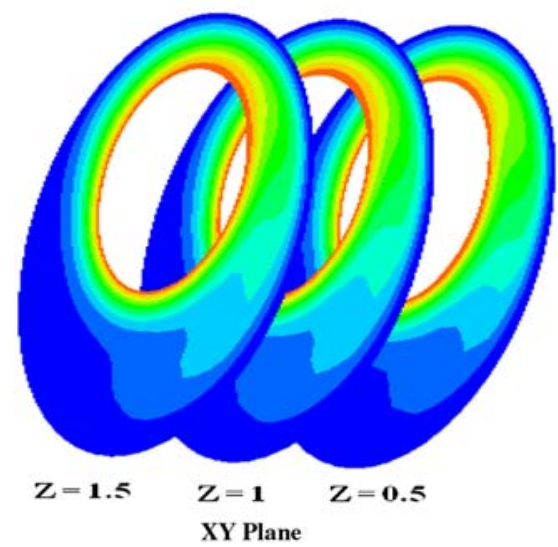

Fig. 18 Isotherms.
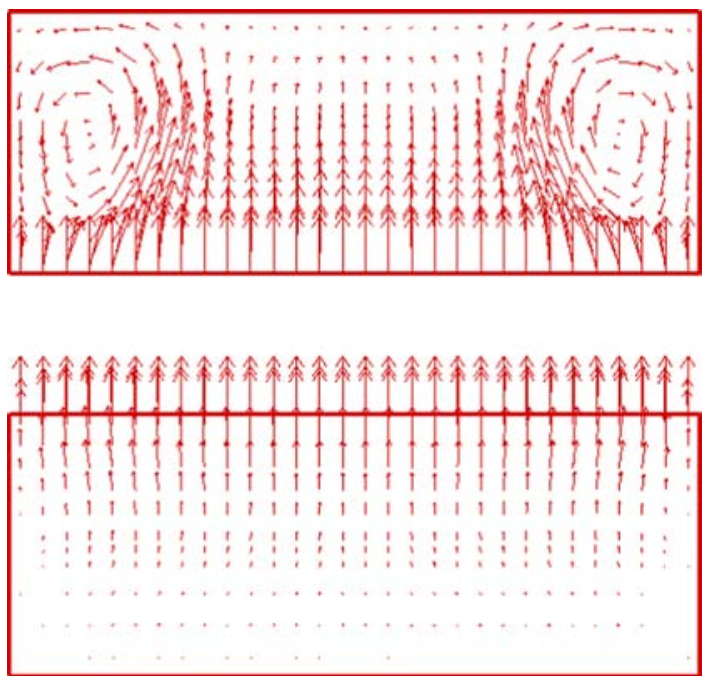

Fig. 19 Velocity vectors (YZ plane).

The results shown in Figs. 9 and 10 are related to a special unsteady condition, which is at different time intervals. The dimensionless parameters are $R a=5000, R e_{o}=+100, R e_{i}=0$, and $E=0.5$. As it can be seen from the velocity vectors at initial time, there is no component in the axial direction and the transfer of energy and momentum takes place by diffusion. Gradually, as time passes $(\tau=0.05)$, the emission of heat and generation of temperature gradients cause the generation of buoyancy force with components in the radial and axial directions, where we can observe the circulation not only in the XY plane, but also the YZ plane at the top part near the two ends. This circulation affects isotherms so that energy transfer produces a nub in isotherms at the top, gradually. It means that the speed of forced convection is higher than natural convection and this fact leads to very small time steps with much longer run times.

The mean Nusselt number at the inner and outer cylinders with respect to time for the preceding situation is depicted in Fig. 10. As it is seen, there is a high gradient at initial time but as time increases the variations are decreased, and thus the results approach the steadystate problem.

One case, as a sample, was investigated to understand the behavior of the flow in the transient process but because many of the applications of this problem use a steady form, the following results are presented in the steady-state case, which avoids the lengthy and time-consuming unsteady code. Results presented in the next six figures are related to $R a=5000, R e_{o}=+100, R e_{i}=0$, and $E=0.5$. Isotherms in the $\mathrm{YZ}$ and the $\mathrm{XY}$ planes are presented in Fig. 11. Here, the 3-D effect of flow is easily seen. As shown, projection of isotherms in the $\mathrm{YZ}$ plane at $Z \approx 0.25 Z_{1}$ is more than that at the middle and the two ends. In this cross section, not only the
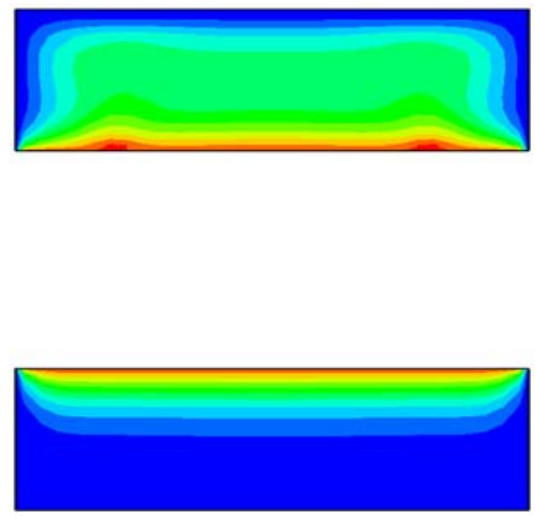

YZ Plane 


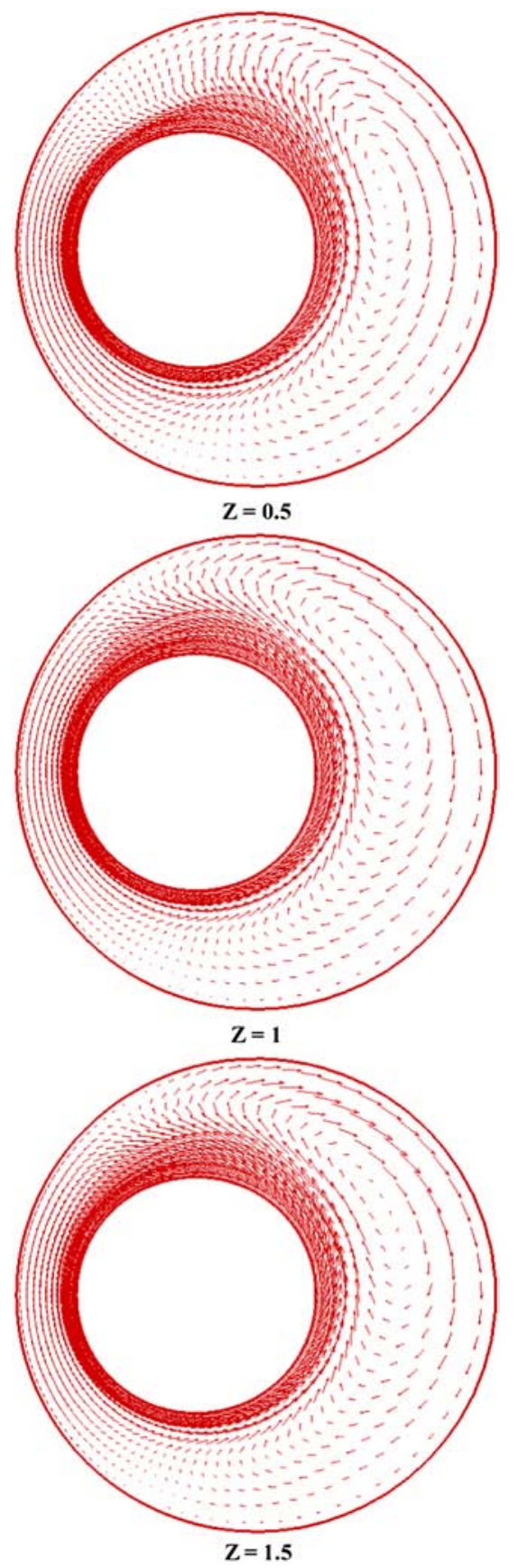

Fig. 20 Velocity vectors.

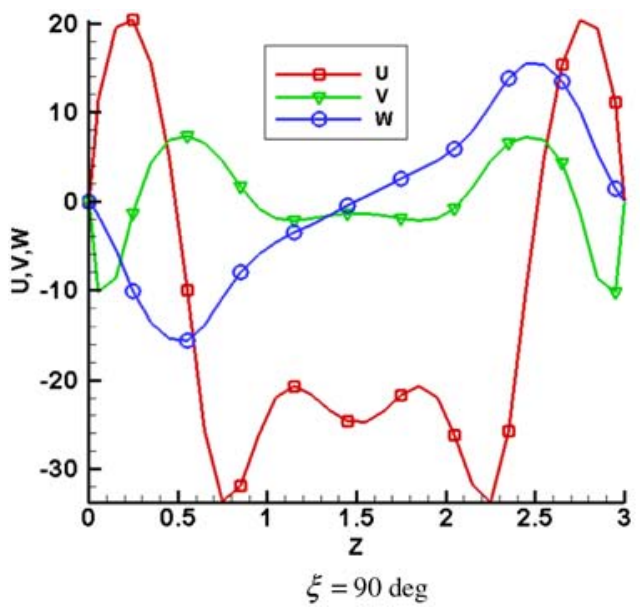

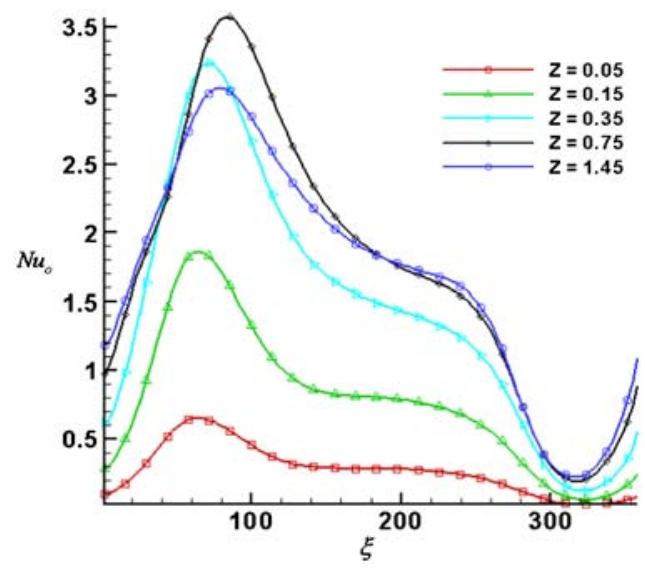

Fig. 22 Local Nusselt number (outer cylinder).

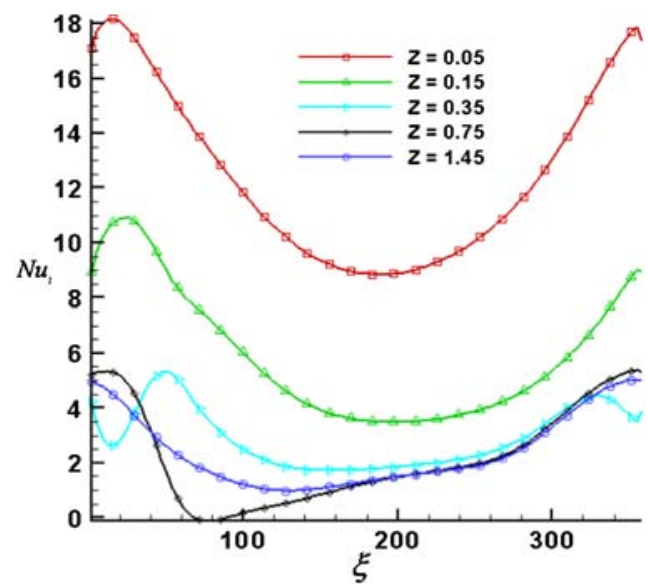

Fig. 23 Local Nusselt number (inner cylinder).

fluid has angular velocity but also an end-effect flow is formed, which is shown in the figure. Isotherms in different axial positions $(Z=0.5$, 1 , and 1.5 ) almost agree in quality with the 2-D results, except at the two ends. Near the ends, at $Z=0.5$, due to the generation of eddies (called Taylor eddies) and the existence of high shear stress, it is possible to move thermal energy in the axial direction. Triple component of velocity in $Z$ direction in a position $\eta=\left(\eta_{i}+\eta_{o}\right) / 2$, $\xi=90 \mathrm{deg}, 270 \mathrm{deg}$ are shown in Fig. 12. Here, a maximum of gradients can be seen at the two ends and the axial component has its maximum value in these positions, which is large enough to be compared with $U$. Velocity vectors in the $\mathrm{YZ}$ plane are depicted in Fig. 13 to better observe the effect of natural convection and

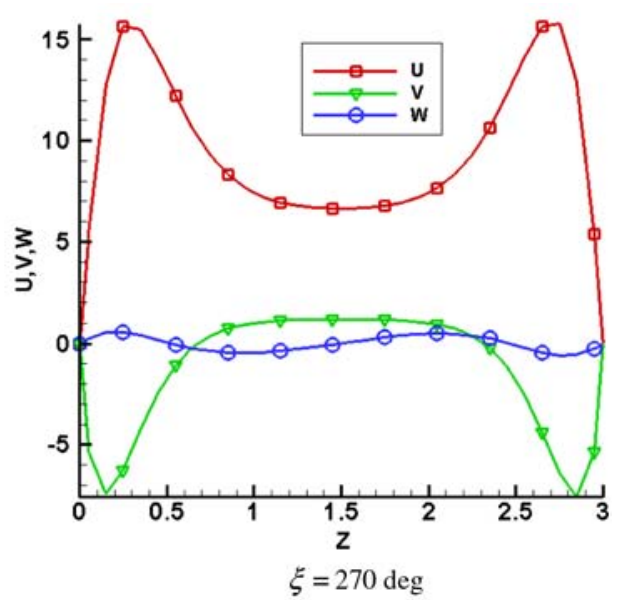

Fig. 21 Velocity components $(R=3 / 2)$. 


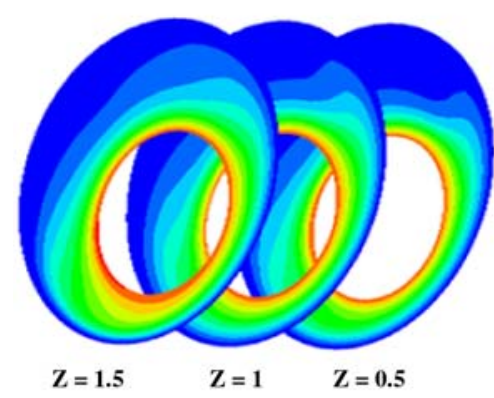

XY Plane
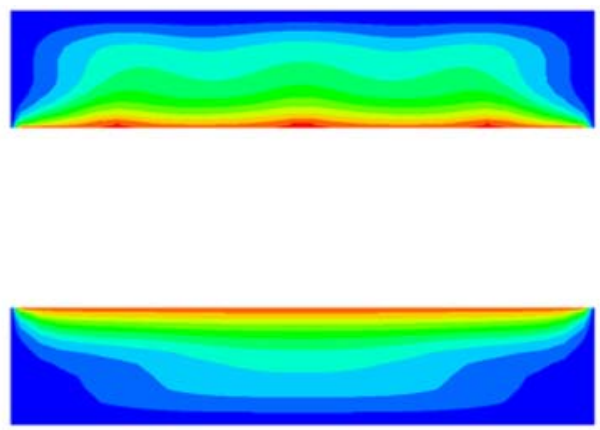

YZ Plane

Fig. 24 Isotherms.

buoyancy force. As it is known, an increase in the length of the annulus causes a decrease in the axial component of the velocity. But considering the 3-D effect, the eddies generated at the two ends at the top part of the annulus intensify. This intensification is due to mixed convection phenomenon and causes the eddies to be formed in a perfect shape. At the top part, natural convection due to temperature difference and forced convection due to rotation of the outer cylinder are opposed to each other and generate intensive gradients, which are discovered in an eddy, whereas in the lower part, the effect of natural and forced convection is neutralized and the circulation of flow is reduced. Velocity vectors in different axial positions are shown in Fig. 14. Moving away from the end planes and due to a decrease of its effect, mixed convection phenomenon changes to forced convection and kidney like eddies near the end plane $(Z=0.5)$ shrink as their distance becomes larger. The Nusselt numbers at the inner and outer cylinders at different axial positions are depicted in Figs. 15 and 16. The Nusselt number at the inner cylinder at $Z=0 . \overline{05}$ has its maximum value. For the outer cylinder, this trend is reversed and the reason for this can be explained by isotherms (Fig. 11). The applied boundary conditions here ( $\theta=0$ on the outer cylinder and two ends) cause the temperature distribution to be uniform and the Nusselt number at the outer cylinder has an ascending trend toward the middle of the annulus. Comparison of the Nusselt number at the outer cylinder between the 3-D and the 2-D model, which was extracted in this study, is shown in Fig. 17. The Nusselt number for the 3-D case is considered in the middle of the annulus and other parameters are as given previously. There are obvious differences and similarities between these two states. The similarity is observed in the trend and the difference in the quantity. Therefore, we can conclude that in case of an estimation in flow pattern, a 2-D approach is applied, which brings about a shorter computer run time. Otherwise, it is required to solve the 3-D equations.

All the preceding results were related to the outer cylinder rotating counterclockwise. Here, we consider conditions when forced convection occurs due to counterclockwise rotation of the inner cylinder $\left(R e_{i}=+100, R e_{o}=0\right)$. In this case, the extracted results have major differences with previous results. Here, high temperature gradients are eliminated and there are small variations in the axial direction. This is evident by noticing the isotherms in Fig. 18 and
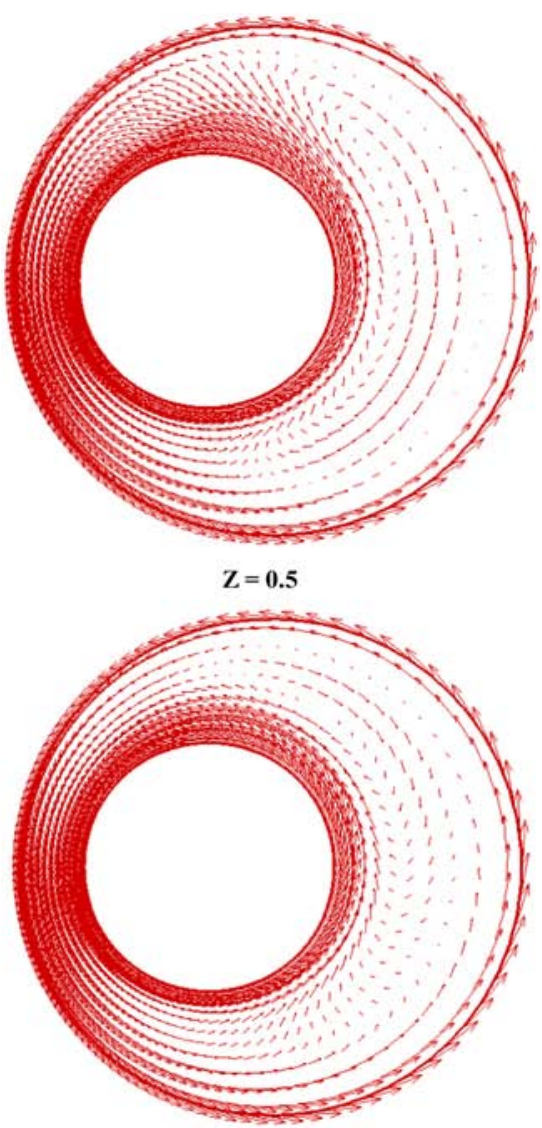

$Z=1$

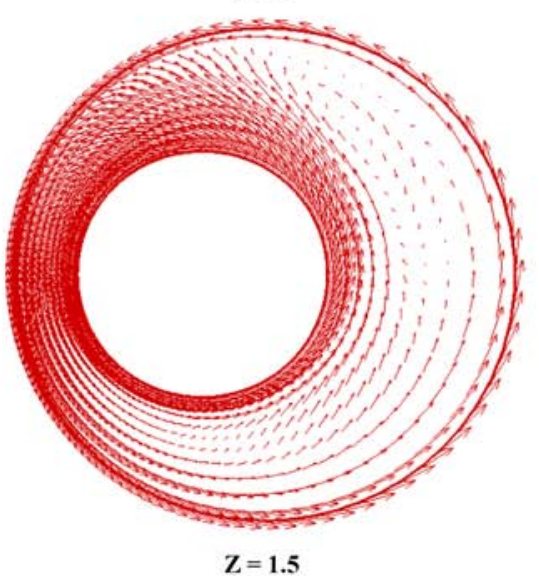

Fig. 26 Velocity vectors. 

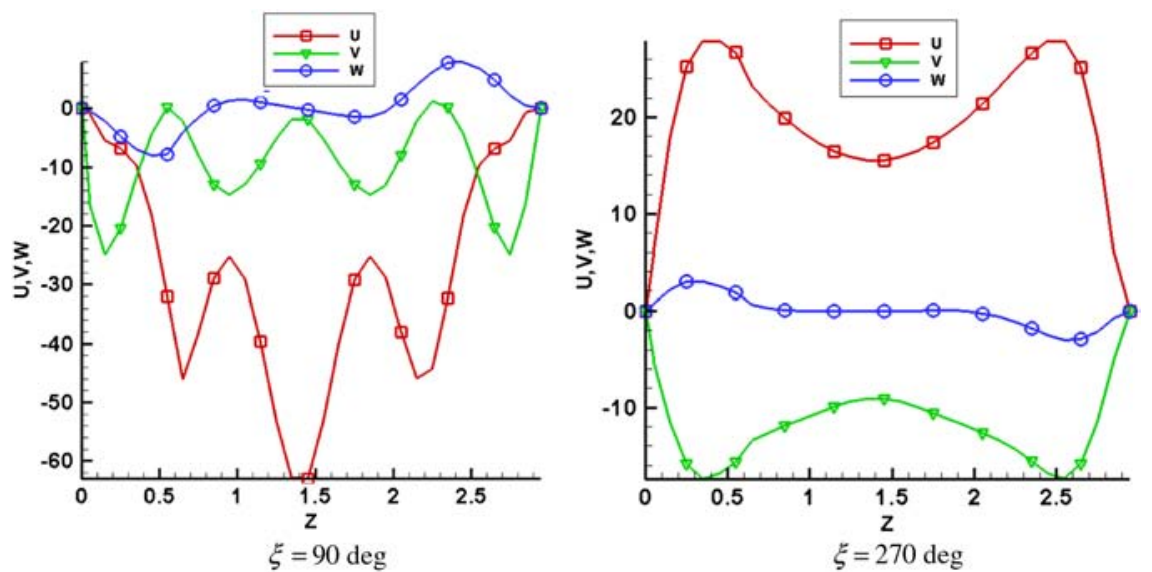

Fig. 27 Velocity components $(R=3 / 2)$.

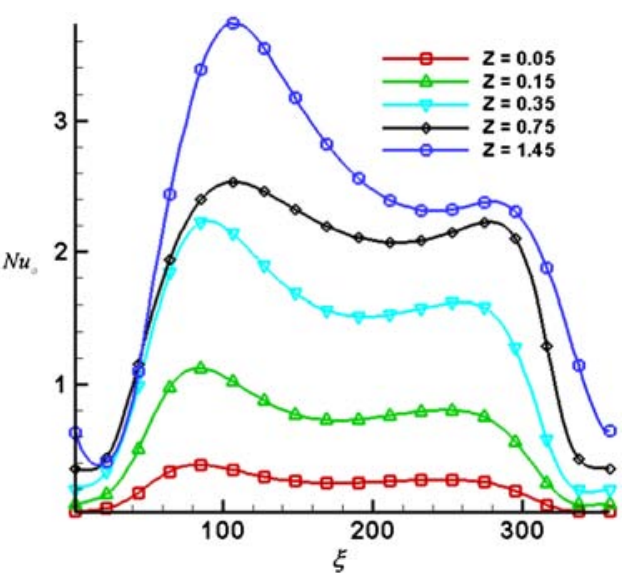

Fig. 28 Local Nusselt number (outer cylinder).

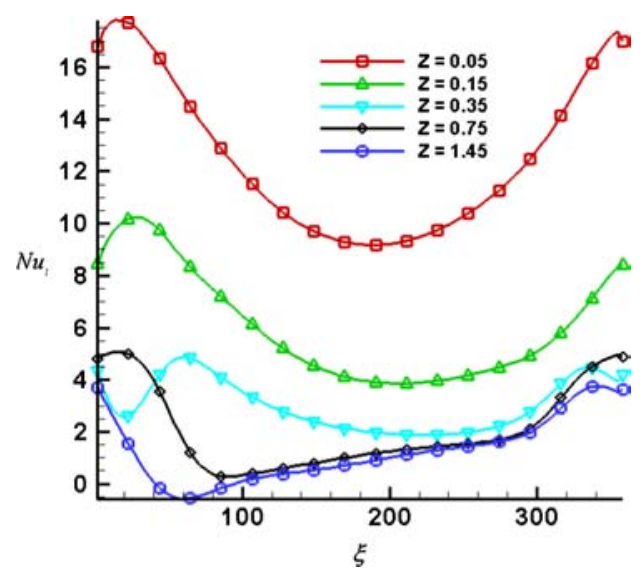

Fig. 29 Local Nusselt number (inner cylinder). velocity vectors in Figs. 19 and 20 . Velocity vectors in the YZ plane (Fig. 20) have significant differences with previous case where two eddies were in the lower part. Notice here that just two eddies are formed in the top part and there is no circulation in the lower part. The reason can be explained as follows: the outer cylinder rotation leads to a decrease in velocity magnitude induced by natural convection, but the inner cylinder rotation leads to an increase in velocity magnitude induced by natural convection. The same conclusion can be reached by using velocity components in Fig. 21 . The axial component has approximately zero value in the lower part, whereas the top part value has a comparable value with $V$ component. All the variations mentioned previously affect the Nusselt number, which can be shown comparing Figs. 15 and 16 with Figs. 22 and 23 .

The following results are related to counterclockwise rotation of both the cylinders with $R e_{o}=R e_{i}=+100$, which were extracted for the same conditions mentioned previously. The flow pattern here is completely different from the two previous cases. If we consider Fig. 24, isotherms have three maximums in the axial direction, where one is in the middle of the annulus and the other two are at the two ends. These maximums can be explained by velocity vectors (Figs. 25 and 26) and eddies that are generated at the top part of the annulus as previously shown, compared to Fig. 20. Besides the two eddies at the top part, here two semi-eddies can be seen in the middle of the annulus, which cause the fluid to move in the axial direction (Fig. 26). This movement causes a thermal energy displacement. One interesting thing in this case is that the value of velocity components (Fig. 27) and their trends are completely different from the previous cases. In the first case (rotation of the outer cylinder only), the $W$ component was comparable with the $V$ component, whereas here $W$ is much smaller than the $V$ component. This can be a justification for smaller maximum in isotherms in Fig. 24. Considerable differences can be seen for Nusselt number at the outer and inner cylinder in Figs. 28 and 29 , respectively, compared to previous cases. This difference becomes larger with increasing distance from the ends. As shown in Figs. 16 and 22, the maximum Nusselt number occurs at $Z=0.75$, whereas here it occurs at $Z=1.5$. This situation can be
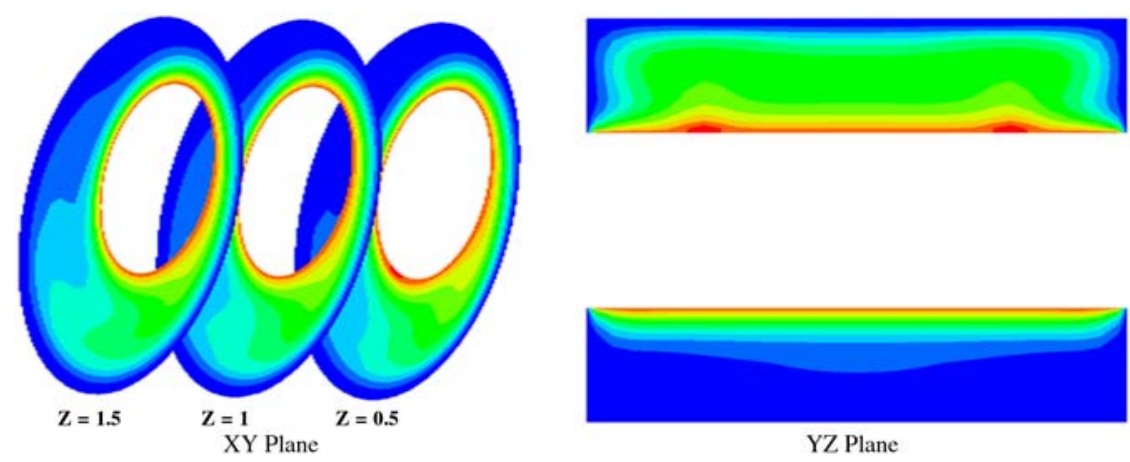

Fig. 30 Isotherms.

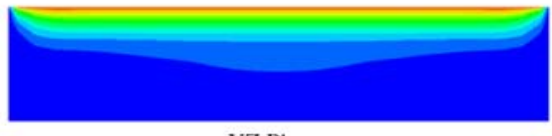

YZ Plane 

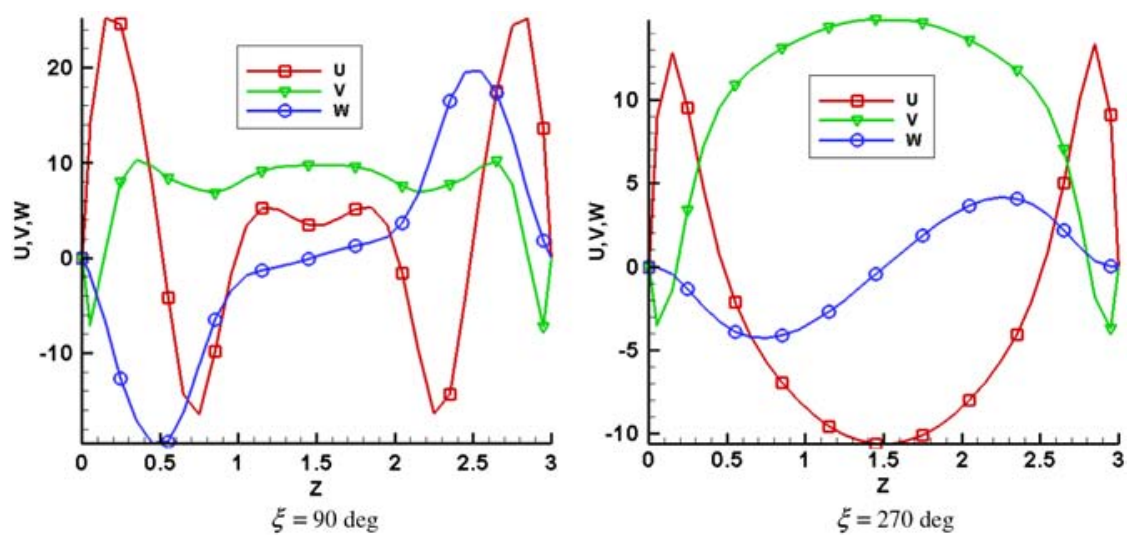

Fig. 31 Velocity components $(R=3 / 2)$.
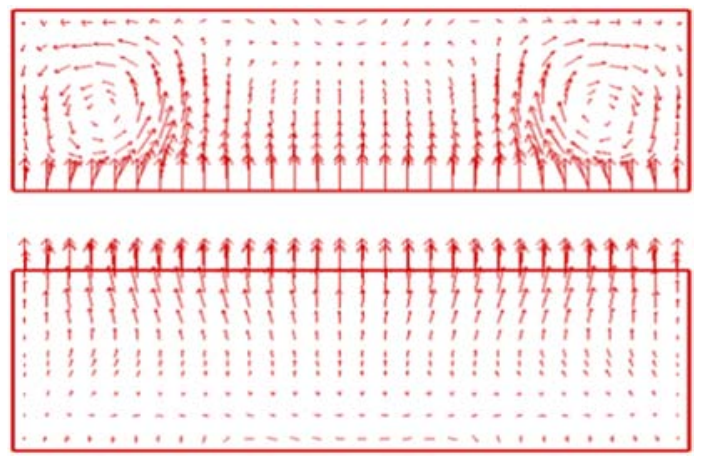

Fig. 32 Velocity vectors (YZ plane).

elaborated by the two semi-eddies, which are formed in the middle of the annulus.

The two following cases that are investigated are related to the two cylinders rotating in different directions. First, we consider the situation in which the outer cylinder is rotated clockwise and the inner one counterclockwise. Both cylinders rotate in the same dimensionless velocity $\left(R e_{o}=-100, R e_{i}=+100\right)$. Here, the obtained results (Fig. 30) are very similar to the second case in quality where just the inner cylinder rotates counterclockwise, but is different in quantity, as shown in Figs. 31-35. As it is seen, the flow develops to 3 -D completely and the axial component increases, where in some positions it is even greater than the $U$ and the $V$ components.

The last case could be counterclockwise and clockwise rotation of the outer and the inner cylinders with $R e_{o}= \pm 100, R e_{i}= \pm 100$. In this case, counter rotation of the cylinders causes high gradients of velocity components with the same orders of magnitude. Here, isotherms have a similar state in the whole annulus, except at the ends. The two eddies that were formed in all the previous cases in the top part are also formed here, but the ones in the lower part have no regular discipline. Complexity of rotation causes the natural convection to produce many changes in the velocity vector directions. Variations of the Nusselt number are very similar to the case where only the outer cylinder was rotated counterclockwise. The related figures were not shown because of the lack of space but are available.

In Table 1, the mean Nusselt numbers for different cases are shown that were investigated previously. If both of the cylinders, for example, are rotated counterclockwise, maximum heat transfer from the outer cylinder takes place, whereas if we want to maximize heat transfer from the inner cylinder, we should rotate the inner one counterclockwise and the outer one clockwise. Note that the Nusselt number values in inner and outer cylinders are not the same. This difference is because of the Nusselt number definition in Eq. (16), in which the heat transfer from the two ends is not accounted for.

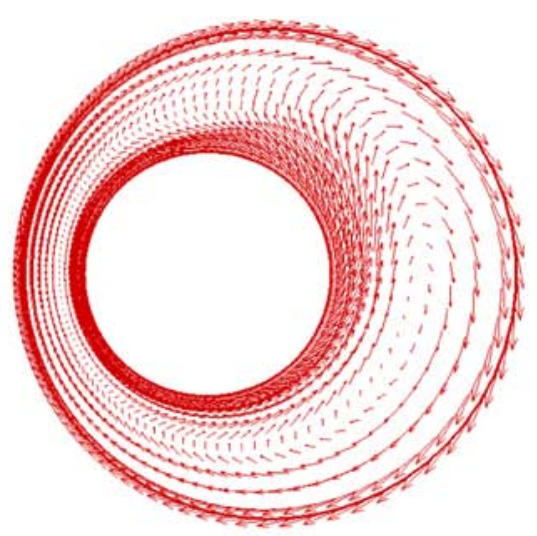

$\mathrm{Z}=0.5$

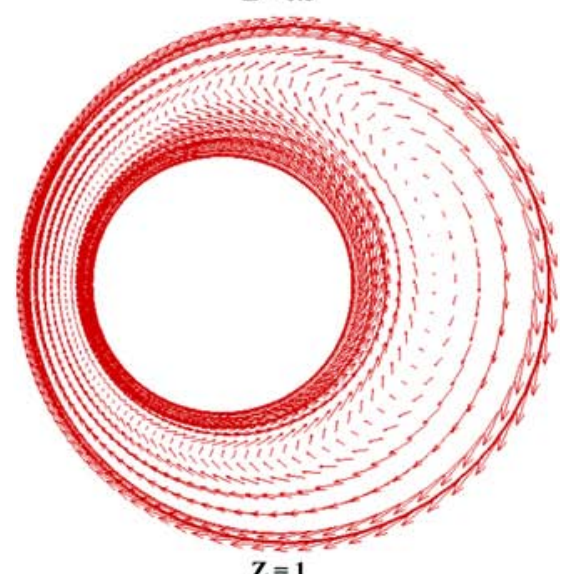

$\mathrm{Z}=1$

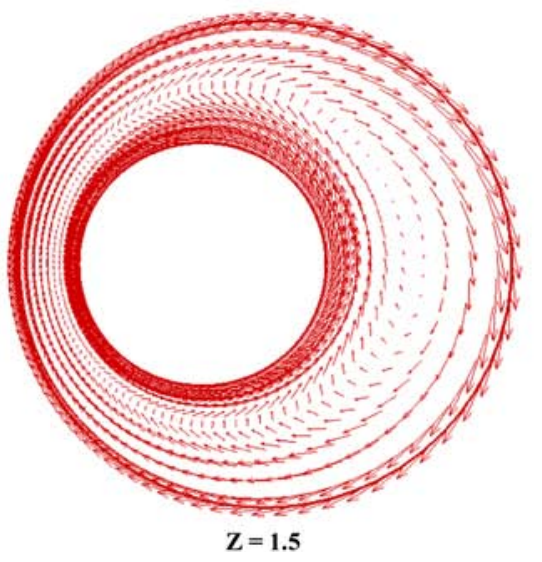

Fig. 33 Velocity vectors. 


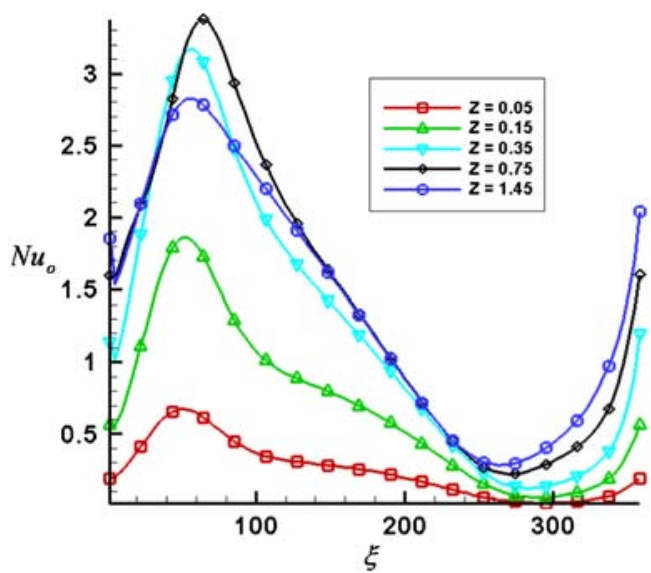

Fig. 34 Local Nusselt number (outer cylinder).

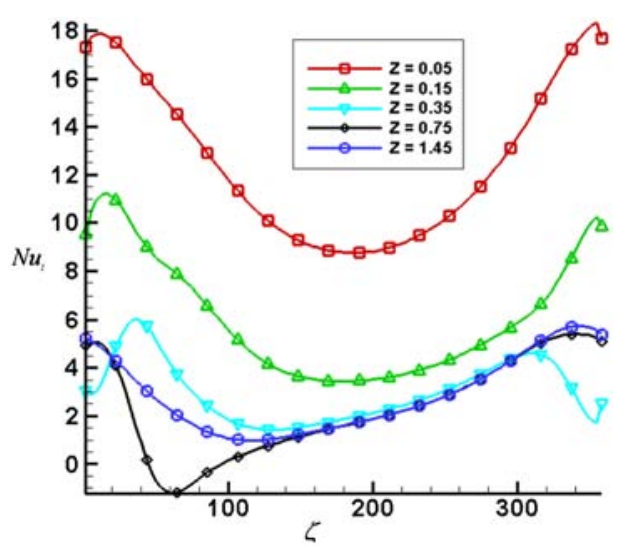

Fig. 35 Local Nusselt number (inner cylinder).

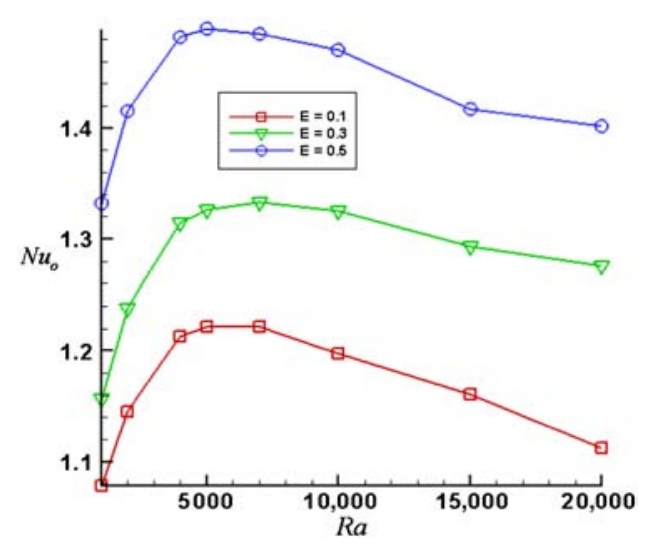

Fig. 36 Mean Nusselt number $\left(G r / R e^{2}=1\right)$.

The effect of the Rayleigh number on the mean Nusselt number for the case where only the outer cylinder rotates is presented in Fig. 36 for sample eccentricities. The Nusselt number increases with increasing eccentricity in a constant Richardson number, which is

\begin{tabular}{c}
\multicolumn{4}{c}{$\begin{array}{c}\text { Table 1 } \\
\text { mean Nusselt number }\end{array}$} \\
\begin{tabular}{|cccc} 
Comparison of \\
\hline$R e_{i}$ & $R e_{o}$ & $\bar{N} u_{o}$ & $\bar{N} u_{i}$ \\
\hline 0 & +100 & 1.5045 & 3.4265 \\
$100+$ & 0 & 1.4891 & 3.4263 \\
$100+$ & +100 & 1.5798 & 3.2327 \\
$100+$ & $100-$ & 1.2292 & 3.6666 \\
$100-$ & +100 & 1.2575 & 3.4170 \\
\hline \hline
\end{tabular}
\end{tabular}

defined by $R i=G r / R e^{2}=1$. The Nusselt number has a maximum near $R a=5000$, which can be used to make optimization in mixed convection problems.

\section{Conclusions}

Mixed convection in 3-D eccentric horizontal annuli has been numerically investigated. The Navier-Stokes equations, along with the energy equation, are solved employing a finite volume method based on the SIMPLE algorithm in the steady and unsteady states. The bipolar coordinate system as a powerful tool was used to produce an orthogonal grid system in the eccentric geometry. The effects of various parameters, such as the eccentricity of the annulus, the Rayleigh number, and different kind of rotation, have been studied considering that 3-D leads to a complicated flow pattern, whereas Taylor vortices have a major role on heat and flow characteristics. It has been shown that, using velocity components in the forced convection problems, even for large cylinder lengths we need to use a 3-D approach. However, in the mixed convection problems, considering 3-D is not essential for large lengths of the annulus. Steady and unsteady results have been presented and it has been shown that because of the different speed in the development of forced convection and natural convection phenomenon, we need to use small time steps so that the effects of both of these phenomena are seen and this leads to an increase in run time of computer codes. In addition, all the quantitative changes occur during the initial times and Nusselt number does not have considerable variations until after $\tau=0.1$.

In the 3-D approach, two ends of the annulus have an axial velocity component, which is comparable to the other components. Generally, two ends of the annulus have high gradients and the generation of Taylor eddies affect the other characteristics of the flow, such as the Nusselt number and isotherms. Different kinds of rotation have a considerable effect on the Nusselt number and flow pattern. Counterclockwise rotation of the outer cylinder only causes a high temperature gradient and besides the circulation in the XY plane, two other circulation zones are formed in the lower part and top parts in the axial direction. Maximum value of the Nusselt number is in the top part of the annulus $(\xi=90)$ for the outer cylinder, whereas this maximum occurs in the right side $(\xi=0)$ for the inner cylinder. In the case of counterclockwise rotation of the inner cylinder, circulation takes place just in the top part of the annulus where the axial component has a larger value compared to the other components. Temperature gradients decrease compared to the outer cylinder rotation case. Counterclockwise rotation of both cylinders has completely different results from the separate rotation of the inner and the outer cylinders. For this case, three small maximums for isotherms were generated that were justified by velocity components. Unlike the previous cases, the Nusselt number had its maximum value at the middle of the annulus. For the case of counter rotation of the two cylinders, the two following states existed. First, the outer cylinder was rotated clockwise and the inner one counterclockwise. Extracted results were similar to the case where only the inner cylinder was rotated counterclockwise but the 3-D effects were more noticeable. Second, the outer cylinder was rotated counterclockwise and the inner cylinder clockwise. In this case, there was no regular discipline in the flow pattern for the lower part, whereas there were high gradients of velocity components in the top part.

It has also been shown that for any eccentricity choice and a specific Richardson number, by varying the Rayleigh number a special maximum value for Nusselt number was detected that can be used for heat transfer optimizations in the mixed convection phenomenon.

\section{Acknowledgment}

Financial support of Ferdowsi University of Mashhad under contract No. 2/25007 is acknowledged. 


\section{References}

[1] Kuehn, T. H., and Goldstein, R. J., "An Experimental and Theoretical Study of Natural Convection in the Annulus Between Horizontal Concentric Cylinders," Journal of Fluid Mechanics, Vol. 74, No. 4, 1976, pp. 695-719.

doi:10.1017/S0022112076002012

[2] Kuehn, T. H., and Goldstein, R. J., "An Experimental Study of Natural Convection Heat Transfer in Concentric and Eccentric Horizontal Cylindrical Annuli," Journal of Heat Transfer, Vol. 100, No. 4, 1978, pp. 635-640. doi: $10.1115 / 1.3450869$

[3] Macleod, A. E., and Bishop, E. H., "Turbulent Natural Convection of Gases in Horizontal Cylindrical Annuli at Cryogenic Temperatures," International Journal of Heat and Mass Transfer, Vol. 32, No. 10, 1989, pp. 1967-1978. doi:10.1016/0017-9310(89)90165-8

[4] Shahraki, F., "Modeling of Buoyancy-Driven Flow and Heat Transfer for Air in a Horizontal Annulus: Effects of Vertical Eccentricity and Temperature-Dependent Properties," Numerical Heat Transfer, Vol. 42, No. 6, 2002, pp. 603-621.

doi:10.1080/10407780290059729

[5] Char, M., and Lee, G., "Maximum Density Effect on Natural Convection of Micro Polar Fluid Between Horizontal Eccentric Cylinders," International Journal of Engineering Science, Vol. 36, No. 2, 1998, pp. 157-169. doi:10.1016/S0020-7225(97)00023-2

[6] Mizushima, J., Hayashi, S., and Adachi, T., "Transitions of Natural Convection in a Horizontal Annulus," International Journal of Heat and Mass Transfer, Vol. 44, No. 6, 2001, pp. 1249-1257. doi:10.1016/S0017-9310(00)00188-5

[7] Petrone, G., Chenier, E., and Lauriat, G., "Stability of Free Convection in Air Filled Horizontal Annuli: Influence of the Radius Ratio," International Journal of Heat and Mass Transfer, Vol. 47, Nos. 17-19, 2004, pp. 3889-3907. doi:10.1016/j.ijheatmasstransfer.2004.04.002

[8] Farouk, B., and Guceri, S. I., "Laminar and Turbulent Natural Convection in the Annulus Between Horizontal Concentric Cylinders," Journal of Heat Transfer, Vol. 104, No. 4, 1982, pp. 631-636. doi: $10.1115 / 1.3245178$

[9] Char, M., and Hsu, Y. H., "Comparative Analysis of Linear and Nonlinear Low-Reynolds Number Eddy Viscosity Models to Turbulent Natural Convection in Horizontal Cylindrical Annuli," Numerical Heat Transfer, Vol. 33, No. 2, 1998, pp. 191-206. doi:10.1080/10407789808913934

[10] Padilla, E. L., Campregher, M. R., and Silveira-Neto, A., "Numerical Analysis of the Natural Convection in Horizontal Annuli at Low and Moderate Ra," Thermal Engineering, Vol. 5, No. 2, 2006, pp. 58-65.

[11] Chai, J. C., and Patankar, S. V., "Laminar Natural Convection in Internally Finned Horizontal Annuli," Numerical Heat Transfer, Part A, Vol. 24, No. 1, 1993, pp. 67-87.

doi:10.1080/10407789308902603

[12] Desrayaud, G., Lauriat, G., and Cadiou, P., "Thermoconvective Instabilities in a Narrow Horizontal Air-Filled Annulus," International Journal of Heat and Fluid Flow, Vol. 21, No. 1, 2000, pp. 65-73. doi:10.1016/S0142-727X(99)00048-X

[13] Patankar, S. V., Ivanovic, M., and Sparrow, E. M., "Analysis of Turbulent Flow and Heat Transfer in Internally Finned Tubes and Annuli," Journal of Heat Transfer, Vol. 101, No. 1, 1979, pp. 29-37.

[14] Rustum, I. M., and Soliman, H. M., "Numerical Analysis of Laminar Mixed Convection in Horizontal Internally Finned tubes," International Journal of Heat and Mass Transfer, Vol. 33, No. 7, 1990, pp. 14851496. doi:10.1016/0017-9310(90)90045-V

[15] Dyko, M., Vafai, K., and Mojtabi, A., "A Numerical and Experimental Investigation of Stability of Natural Convective Flows Within a Horizontal Annulus,' Journal of Fluid Mechanics, Vol. 381, No. 1, 1999, pp. 27-61. doi:10.1017/S0022112098002948

[16] Yoo, J. S., "Mixed Convection of Air Between Two Horizontal Concentric Cylinders with a Cooled Rotating Outer Cylinder," International Journal of Heat and Mass Transfer, Vol. 41, No. 2, 1998, pp. 293-302. doi:10.1016/S0017-9310(97)00141-5

[17] Habib, M. A., and Negm, A. A., "Laminar Mixed Convection in Horizontal Concentric Annuli with Non-Uniform Circumferential Heating," Heat and Mass Transfer, Vol. 37, Nos. 4-5, 2001, pp. 427435 . doi: $10.1007 / \mathrm{s} 002310000153$
[18] Glakpe, E. K., Watkins, J., and Cannon, J. N., "Constant Heat Flux Solution for Natural Convection Between Concentric and Eccentric Horizontal Cylinders," Numerical Heat Transfer, Vol. 10, No. 3, 1986, pp. 279-295. doi:10.1080/10407788608913520

[19] Glakpe, E. K., and Watkins, J., "Effect of Mixed Boundary Condition on Natural Convection in Concentric and Eccentric Annular Enclosure," AIAA Paper 1587-1591, 1987.

[20] Hessami, M. A., Pollar, A., and Rowe, R. D., "Numerical Calculation of Natural Convection Heat Transfer Between Horizontal Concentric Isothermal Cylinders: Effect of Variation of Fluid Properties," Journal of Heat Transfer, Vol. 106, No. 1, 1984, pp. 668-671. doi:10.1115/1.3246736

[21] Kumar, P., "Study of Natural Convection in Horizontal Annuli," International Journal of Heat and Mass Transfer, Vol. 31, No. 6, 1988, pp. 1137-1148. doi:10.1016/0017-9310(88)90056-7

[22] Soliman, H. M., and Mirza, S., "The Influence of Internal Fins on Mixed Convection Inside Horizontal Tubes," International Communications in Heat and Mass Transfer, Vol. 12, No. 2, 1985, pp. 191-200.

[23] Tsui, T., and Tremblay, B., "On Transient Natural Convection Heat Transfer in the Annulus Between Concentric Horizontal Cylinders with Isothermal Surfaces," International Journal of Heat and Mass Transfer, Vol. 21, No. 1, 1984, pp. 103-111. doi:10.1016/0017-9310(84)90242-4

[24] Yang, H. Q., Yang, K. T., and Loyd, J. R., "Natural Convection Suppression in Horizontal Annuli by Azimuthal Baffles," International Journal of Heat and Mass Transfer, Vol. 31, No. 10, 1988, pp. 21232136. doi:10.1016/0017-9310(88)90122-6

[25] Van de Sande, E., and Hamer, B. J. G., "Steady and Transient Natural Convection in Enclosures Between Circular Cylinders (Constant Heat Flux)," International Journal of Heat and Mass Transfer, Vol. 22, No. 3 , 1979, pp. 361-370. doi:10.1016/0017-9310(79)90002-4

[26] Pepper, D. W., and Cooper, R. E., "Numerical Solution of Natural Convection in Eccentric Annuli," AIAA Journal, Vol. 21, No. 9, 1983, pp. 1331-1337. doi: $10.2514 / 3.8247$

[27] Teertstra, P., Yovanovich, M. M., and Culham, J. R., "Analytical Modeling of Natural Convection in Concentric Spherical Enclosures," Journal of Thermophysics and Heat Transfer, Vol. 20, No. 2, 2006, pp. 297-304. doi:10.2514/1.16811

[28] Khan, W. A., Culham, J. R., and Yovanovich, M. M., "Analytical Model for Convection Heat Transfer from Tube Banks," Journal of Thermophysics and Heat Transfer, Vol. 20, No. 4, 2006, pp. 720-727. doi:10.2514/1.15453

[29] Khan, W. A., Culham, J. R., and Yovanovich, M. M., "Fluid Flow and Heat Transfer from Elliptical Cylinders: Analytical Approach," Journal of Thermophysics and Heat Transfer, Vol. 19, No. 2, 2005, pp. 178-185. doi: $10.2514 / 1.10456$

[30] Vafai, K., and Ettefagh, J., "An Investigation of Transient Threedimensional Buoyancy-Driven Flow and Heat Transfer in a Closed Horizontal Annulus," International Journal of Heat and Mass Transfer, Vol. 34, No. 10, 1991, pp. 2555-2570. doi:10.1016/0017-9310(91)90096-W

[31] Vafai, K., and Desai, C. P., "Comparative Analysis of the Finite-Element and Finite-Difference Methods for Simulation of Buoyancy-Induced Flow and Heat Transfer in Closed and Open Ended Annular Cavities," Numerical Heat Transfer, Vol. 23, No. 1, 1993, pp. 35-59. doi:10.1080/10407789308913661

[32] Yeh, C., "Numerical Investigation of the Three-Dimensional Natural Convection Inside Horizontal Concentric Annulus with Specific Wall Temperature or Heat Flux," International Journal of Heat and Mass Transfer, Vol. 42, No. 4, 2002, pp. 775-784. doi:10.1016/S0017-9310(01)00191-0

[33] Lee, T. S., "Numerical Computation of Fluid Convection with Air Enclosed Between the Annuli of Eccentric Heated Horizontal Rotating Cylinders," International Journal. of Computers and Fluids, Vol. 1, No. 3, 1992, pp. 355-368. doi:10.1016/0045-7930(92)90044-V

[34] Yang, L., and Farouk, B., "Three-Dimensional Mixed Convection Flow in a Horizontal Annulus with a Heated Rotating Inner Circular Cylinder," International Journal of Heat and Mass Transfer, Vol. 35, No. 8, 1992, pp. 1947-1956.

[35] Patankar, S. V., Numerical Heat Transfer and Fluid Flow, McGrawHill, New York, NY, 1980. 